Different Fates of Alzheimer's Disease Amyloid-Beta Fibrils Remodeled by Biocompatible Small Molecules

A Thesis
Presented to
the faculty of the School of Engineering and Applied Science
University of Virginia
in partial fulfillment
of the requirements for the degree
Master of Science
by

by

Jacob A. Irwin

May

2013 
APPROVAL SHEET

The thesis

is submitted in partial fulfillment of the requirements

for the degree of

Master of Science

AUTHOR

The thesis has been read and approved by the examining committee:

Inchan Kwon

Advisor

David Green

Giorgio Carta

Accepted for the School of Engineering and Applied Science:

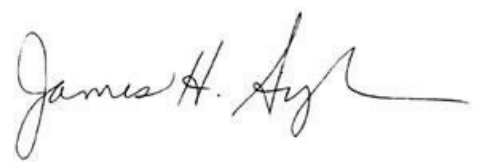

Dean, School of Engineering and Applied Science

May

2013 


\title{
Different Fates of Alzheimer's Disease Amyloid-Beta Fibrils Remodeled by Biocompatible Small Molecules
}

\author{
A Thesis \\ Presented to \\ the faculty of the School of Engineering and Applied Science \\ University of Virginia \\ In Partial Fulfillment
}

Of the requirements for the Degree

Masters of Science (Chemical Engineering)

By

Jacob A. Irwin

May 2013 


\begin{abstract}
$\underline{\text { Abstract }}$
Amyloid fibril protein aggregates implicated in numerous human diseases are thermodynamically very stable. Stringent conditions that would not be possible in a physiological environment are often required to disrupt the stable fibrils. Recently, there is increasing evidence that small molecules can remodel amyloid fibrils in a physiologically relevant manner. In order to investigate possible fibril remodeling mechanisms using this approach, we performed comparative studies on the structural features of the different amyloid-beta $(A \beta)$ aggregates remodeled from $A \beta$ fibrils by three biocompatible small molecules: methylene blue (MB); brilliant blue G (BBG); and erythrosine B (ER). Combined with circular dichroism (CD), immuno-blotting, transmission electron microscopy (TEM), and atomic force microscopy (AFM) results, it was found that brilliant blue G- and erythrosine B-treatment generate fragmented $\mathrm{A} \beta$ fibrils and protofibrils, respectively. In contrast, incubation of the $A \beta$ fibrils with methylene blue perturbs fibrillar structure leading to amorphous $A \beta$ aggregates. These findings provide insights on the molecular mechanism of amyloid fibril formation and remodeling and also illustrate the possibility of controlled changes in biomolecule nanostructures.
\end{abstract}




\section{Acknowledgements}

I would like to thank the following people:

My research advisor, Professor Inchan Kwon, for his continued guidance, faith, and insight in helping me navigate and understand the dynamics of graduate school and research.

Professors Giorgio Carta and David Green for serving on my Thesis Committee.

Professor Alev Erisir and Anqi Fu at the Psychology Department at the University of Virginia for assistance with TEM assays.

Professor Jerold Floro, Joseph Kassim, and Jatin Amatya at the Material Science Department at the University of Virginia for assistance with AFM assays.

My lab mates from the Kwon group for their support and guidance, including Simpson Gregoire, Shun Zheng, Sung In Lim, and in particular, Edward Wong, for helping to teach me many of the lab techniques needed to get started on my research upon joining the research group.

Finally, my friends and family. Specifically, to my parents, Robert and Cathy, and sister, Madeline, for teaching me to find my passion in life and never stop trying to do my best. And, to my best friend, Becca, for her unwavering kindness and love for me, and for putting up with me during all of the late nights and odd hours I sometimes find myself doing experiments at the lab while in graduate school.

This work was supported by the KSEA Young Investigator Grant and a National Science Foundation Graduate Research Fellowship (DGE-00809128). 


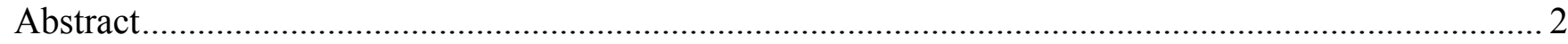

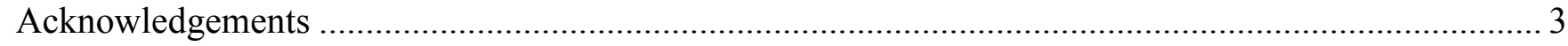

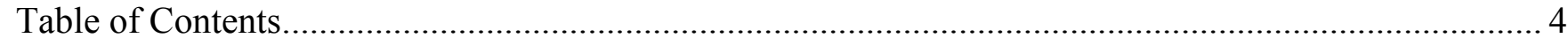

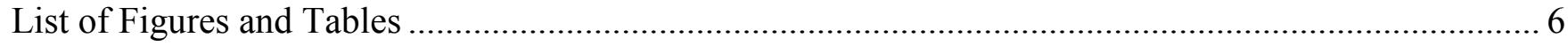

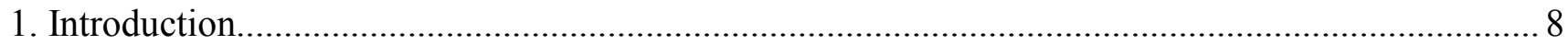

1.1 A $\beta 40$ Aggregation Pathway ……………………...................................................... 9

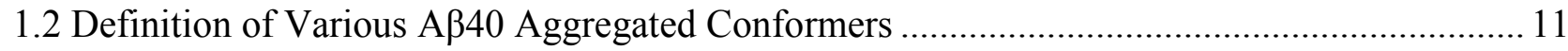

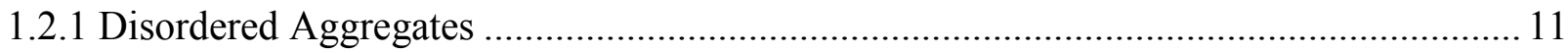

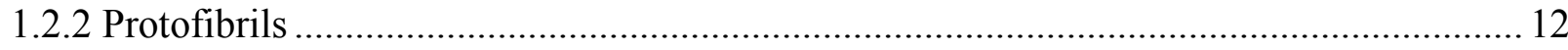

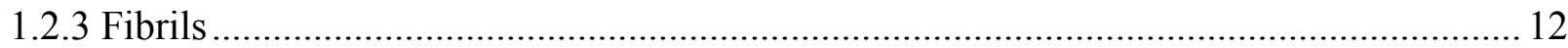

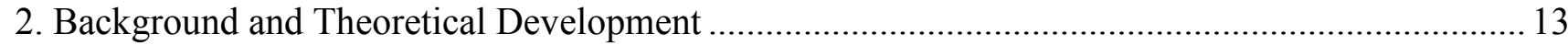

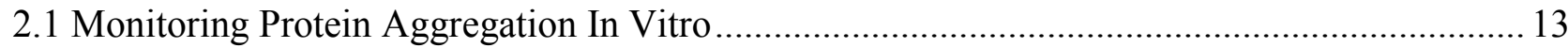

2.1.1 Molecular Probes for Aggregate Characterization ........................................................ 15

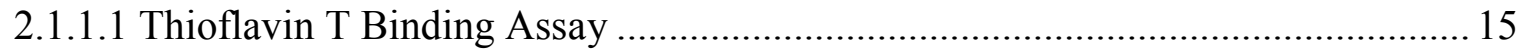

2.1.1.2 Congo Red Binding Assay............................................................................... 16

2.1.1.3 Antibody Dot Blot Assay.............................................................................. 16

2.1.2 Methods for Obtaining Morphological Information on Protein Aggregate Species ......... 18

2.1.2.1 Electron Microscopy \& Atomic Force Microscopy ................................................. 18

2.1.3 Methods for Obtaining Secondary Structure Information on Protein Aggregate Species. 19

2.1.3.1 Circular Dichroism \& Fourier Transform Infrared Spectroscopy .......................... 19

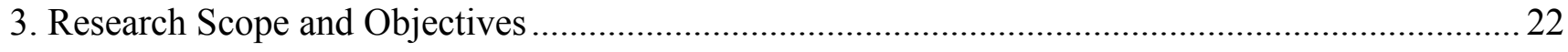

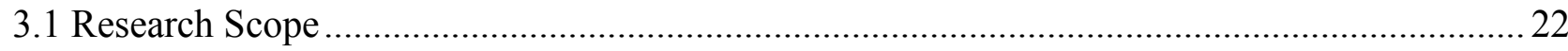

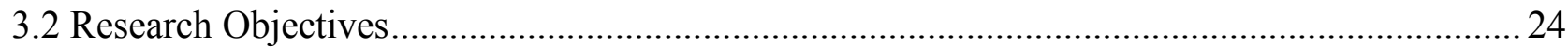

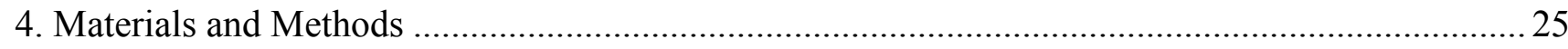

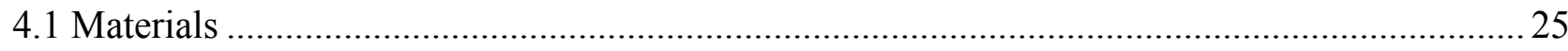

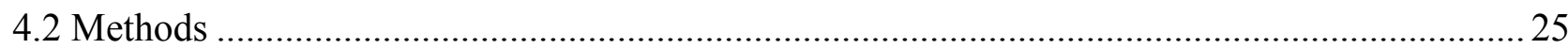

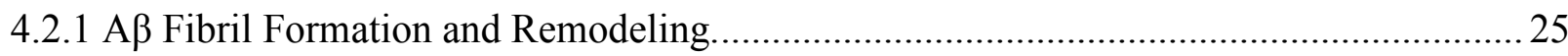

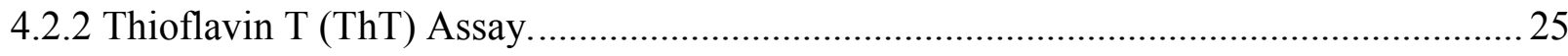

4.2.3 Transmission Electron Microscopy (TEM) ………...................................................... 26

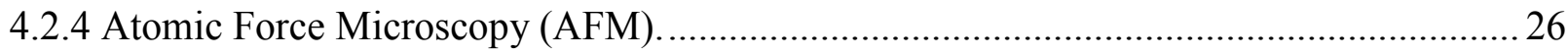

4.2.5 Circular Dichroism (CD) and Numerical Spectra Deconvolution.................................... 26

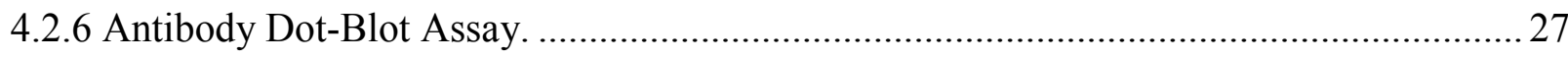

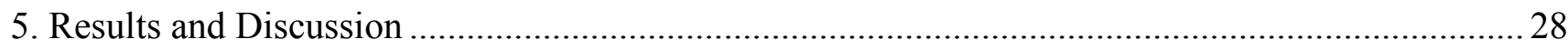

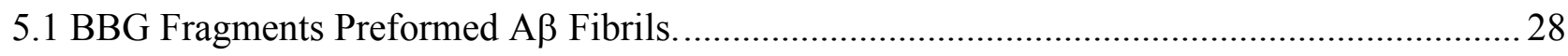

5.2. MB Converts Preformed A $\beta$ fibrils into Amorphous Aggregates.............................................. 38 
5.3. ER Disrupts Preformed $A \beta$ fibrils into Protofibrils....................................................... 42

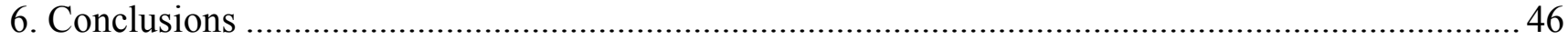

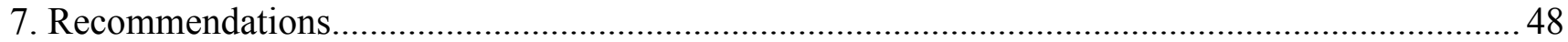

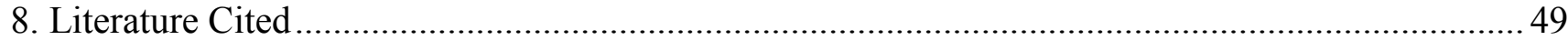

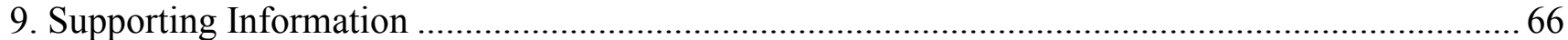




\section{List of Figures and Tables}

Figure 1. A commonly studied A $\beta 40$ aggregation pathway .10

Figure 2. Scheme of protein folding and misfolding/aggregation.

Figure 3. Chemical structure of brilliant blue $\mathrm{G}(\mathrm{BBG})$, methylene blue (MB), and erythrosine $\mathrm{B}$ (ER) at neutral $\mathrm{pH}^{1}$ 23

Figure 4. Properties of the $A \beta$ fibrils incubated in the absence or presence of BBG. TEM (A) and AFM images $(\mathrm{B}, 1 \mathrm{x} 1 \mu \mathrm{m})$ of the $\mathrm{A} \beta$ fibrils incubated for one day in the absence of any dye (Panel A $\beta$ only) or presence of 10x BBG (Panel BBG). The sections of the two TEM images were magnified (Panels $A \beta$ only_M and BBG_M). Each pair of arrows illustrates the width of the A $\beta$ aggregates. TEM scale bar is $100 \mathrm{~nm}$ (Top Panels) or $20 \mathrm{~nm}$ (Bottom Panels). (C) CD spectra of $A \beta$ monomers, $A \beta$ fibrils incubated in the absence (A $\beta$ fibrils) or presence of $10 \mathrm{x}$ $\mathrm{BBG}(\mathrm{A} \beta$ fibrils $+\mathrm{BBG})$ for one day 34

Figure 5. Dot-blot images of the $A \beta$ fibrils incubated in the absence (A $\beta$ only) or presence of $1 x$ and 10x BBG, MB, or ER for less than 5 minutes (Panel $<5 \mathrm{~min}$ ) or one day (Panel 1-day incubation). For each antibody, all samples were spotted onto the same nitrocellulose membrane. Each membrane was stained with the OC, 6E10, or $4 \mathrm{G} 8$ antibody. For clearer presentation of the data, the sections of each membrane were cut and re-arranged....

Figure 6. Properties of the A $\beta$ fibrils incubated in the absence or presence of MB. (A) TEM (left

panel) and AFM (right panel, $1 \times 1 \mu \mathrm{m}$ ) images of the $\mathrm{A} \beta$ fibrils incubated for one day in the 
presence of $10 \mathrm{x}$ MB. TEM scale bar is $100 \mathrm{~nm}$. (B) CD spectra of A $\beta$ monomers, $A \beta$ fibrils incubated in the absence (A $\beta$ fibrils) or presence of 10x MB (A $\beta$ fibrils $+\mathrm{MB})$ for one day $\ldots . . .41$

Figure 7. Properties of the A $\beta$ fibrils incubated in the absence or presence of ER. TEM (A) and $\operatorname{AFM}(\mathrm{B}, 1 \mathrm{x} 1 \mu \mathrm{m})$ images of the $\mathrm{A} \beta$ fibrils incubated for one day in the presence of 10x ER (Panel ER) and the magnified section (Panel ER_M). The pair of arrows illustrate the width of the A $\beta$ aggregates. TEM scale bar is $100 \mathrm{~nm}$ (Panel ER) or $20 \mathrm{~nm}$ (Panel ER_M). (C) CD spectra of $A \beta$ monomers, $A \beta$ fibrils incubated in the absence (A $\beta$ fibrils) or presence of 10x ER (A $\beta$ fibrils + ER) for one day.

Table 1: Measured TEM length (A) and width (B) distribution of A $\beta$ fibrils incubated in the presence or absence of $10 \mathrm{X} B B G$ and $10 \mathrm{X}$ ER for one day at $37^{\circ} \mathrm{C}$. Lengths and widths were measured using Image J software. The aggregate length or width bin labels represent the maximum length or width of aggregates in each respective bin. Shown on the table are the proportions of each sample population measured possessing the respective maximum bin length or width. Minimum one hundred aggregates except fifty one fibrils only aggregates for length distribution were used to obtain the distribution. ND: Not Detected. .35

Table 2: Secondary structure content of $A \beta$ fibrils incubated in the absence or presence of BBG or ER at $37{ }^{\circ} \mathrm{C}$ without shaking for one day. Determined by DichroWeb using CONTIN method and SP175 reference proteins. $\mathrm{A} \beta$ :small molecule $(\mathrm{BBG}$ or $\mathrm{ER})=1: 10$ molar ratio. .36

Table 3: Secondary structure content of $\mathrm{A} \beta$ fibrils incubated in the absence or presence of $\mathrm{MB}$ at $37{ }^{\circ} \mathrm{C}$ without shaking for one day. Determined by DichroWeb using CONTIN method and Set 6 reference proteins. $\mathrm{A} \beta: \mathrm{MB}=1: 10$ molar ratio 


\section{$\underline{\text { 1. Introduction }}$}

The amyloid fibril is one of the most biologically important protein structures due to its implication in numerous neurodegenerative diseases, such as Alzheimer's disease (AD), Parkinson's disease (PD), and prion disease. ${ }^{1-5}$ Intrinsically disordered monomeric peptide and protein, such as amyloid-beta (A $\beta$ ) peptide and $\alpha$-synuclein, aggregate to form prefibrillar or fibrillar oligomers, leading to amyloid fibrils with cross-stacked $\beta$-sheet structure. ${ }^{6}$

Since amyloid fibrils are thermodynamically very stable, ${ }^{1,7}$ it has been generally accepted that reversing the preformed amyloid fibrils into smaller intermediates does not occur spontaneously. Therefore, several strategies employing physiological and non-physiological conditions have been investigated to break, disrupt, and/or destabilize amyloid fibrils. ${ }^{8}$ As a non-physiological condition, physical energy has been applied to break down mature fibrils. Ultrasonication has been found to fragment preformed amyloid fibrils into shorter fibril fragments that can be used to template further fibril formation. ${ }^{9}$ Additionally, high temperatures (above $100^{\circ} \mathrm{C}$ ) have been found to disrupt the strength of hydrogen-bond networks which are crucial for the rigid fibril structure, leading ultimately to destruction of fibril structure. ${ }^{8,10}$ Because charge is a very important factor in fibril structure stability, drastic changes in $\mathrm{pH}$ or salt levels can lead to fibril destruction. Specifically, $\mathrm{pH}$ levels above 8 have been shown to lead to complete loss of $\beta$-sheet interactions. ${ }^{11}$ Similarly, the addition of strong ionic liquids can block the electrostatic repulsion forces needed to hold together neighboring protofibrils during the fibril twisting process. ${ }^{12}$ Finally, the introduction of denaturants (such as guanidine hydrochloride) or co-solvents (such as hexafluoroisopropanol (HFIP) and dimethylsufoxide) have also been shown to strongly destabilize preformed amyloid fibrils. ${ }^{13,14}$ Water-ethanol solutions have been found to have a lesser effect over shorter time periods ( $<1$ day), but still converted mature fibrils into shorter, worm-like fibrils over a period of several weeks. ${ }^{15}$

Besides these non-physiological conditions, recent findings demonstrate that preformed amyloid fibrils can be destabilized by endogenous or exogenous compounds in physiological conditions. ${ }^{1}$ L- 
dihydroxy-phenylalanine (L-DOPA), an endogenous precursor of dopamine, disaggregated the amyloid fibrils formed in the mouse brain generating toxic smaller aggregates, ${ }^{16}$ illustrating the possibility that insoluble amyloid fibrils are a source of toxic soluble oligomers/protofibrils ${ }^{17}$ by interacting with destabilizing chemical compounds. Surfactants (such as Triton X-100 and sodium dodecyl sulfate) have been used to destabilize fibrils through the promotion of molecular orientations with unfavorable energy. An interesting example of the interaction of surfactants with mature amyloid fibrils is the work by Ruhs, et al., employing sulfonic-acid-terminated PEG. ${ }^{18}$ The strong electrostatic interactions between the PEG and fibrils reduced the entropy of the native amyloid fibril structure, resulting in its conversion to an amorphous, globular ending structure. It was also reported that several small molecules often introduced into human body (exogenous small molecules), such as doxycycline, epigallocatechin gallate, rifampicin, and dequalinium, destabilize preformed amyloid fibrils. ${ }^{19-21}$ Despite the increasing number of cases demonstrating that amyloid fibrils can be destabilized by small molecules, the underlying molecular mechanisms still remain largely unclear. ${ }^{8}$ In particular, different fates of the destabilized amyloid fibrils have not yet been extensively investigated. Considering that endogenous and exogenous compounds can directly destabilize amyloid fibrils present in the human body, investigating the different fates of the destabilized amyloid fibrils by small molecules will provide insights on the molecular-level pathological mechanism of amyloid fibrils as well as small $\underline{\text { molecule-induced structural conversion of biomacromolecules. }}{ }^{1}$

\subsection{Aß40 Aggregation Pathway}

$\mathrm{A} \beta$ was chosen as the protein to use to study small molecule-induced amyloid fibril destabilization due to their connection with Alzheimer's Disease (AD). The aggregation process for this protein begins when the $A \beta$ protein fragment (monomer) is generated by sequential cleavage of the Amyloid Precursor Protein by gamma and beta-secretase. Depending upon where gamma-secretase cleavage occurs, A $\beta$ peptide fragments ranging from 39-43 amino acids in length can be generated, but the 40 and 42 amino acid length peptides (designated $A \beta 40$ and $A \beta 42$, respectively) are the alloforms 
most often found in amyloid aggregates in the AD brain. Although the A $\beta 42$ load in the AD brain is only $10 \%$ that of $\mathrm{A} \beta 40, \mathrm{~A} \beta 42$ has been shown to be more hydrophobic, more aggregation prone, and more neurotoxic than the $\mathrm{A} \beta 40$ isoform. ${ }^{22} \mathrm{~A} \beta 40$ was chosen as the platform for this thesis work because it 1) is more user friendly in that is it less sensitive to person-to-person handling during sample preparation, 2) is nine times physically more prevalent in the $\mathrm{AD}$ brain than $\mathrm{A} \beta 42,{ }^{22}$ and 3 ) has an aggregation pathway that has been found to generally be modulated in a similar fashion by small molecule inhibitors as the $A \beta 42$ aggregation pathway. ${ }^{23}$

After the $A \beta 40$ peptide monomer is generated, multiple independent and dependent aggregation cascades can occur resulting in the formation of various aggregated states of $A \beta 40$ protein, known as conformers. In one frequently studied pathway, misfolded disordered A $\beta 40$ monomers first selfassemble in to soluble (commonly termed "on-pathway," since they mature to the fibril state) prefibrillar oligomers prior to forming a stacked $\beta$-sheet rich aggregate known as protofibrils. Further aggregation of these protofibrils ultimately results in the more thermodynamically stable insoluble A $\beta 40$ fibril conformer. ${ }^{24} \mathrm{~A}$ schematic of this $\mathrm{A} \beta 40$ aggregation pathway with the various species is shown in Figure 1. Aside from these on-pathway conformers, unstructured "off-pathway" aggregates have also been found to occur during the $\mathrm{A} \beta$ aggregation process employing different in vitro aggregation conditions. $^{25}$

\section{Monomers Oligomers Protofibrils Fibrils}

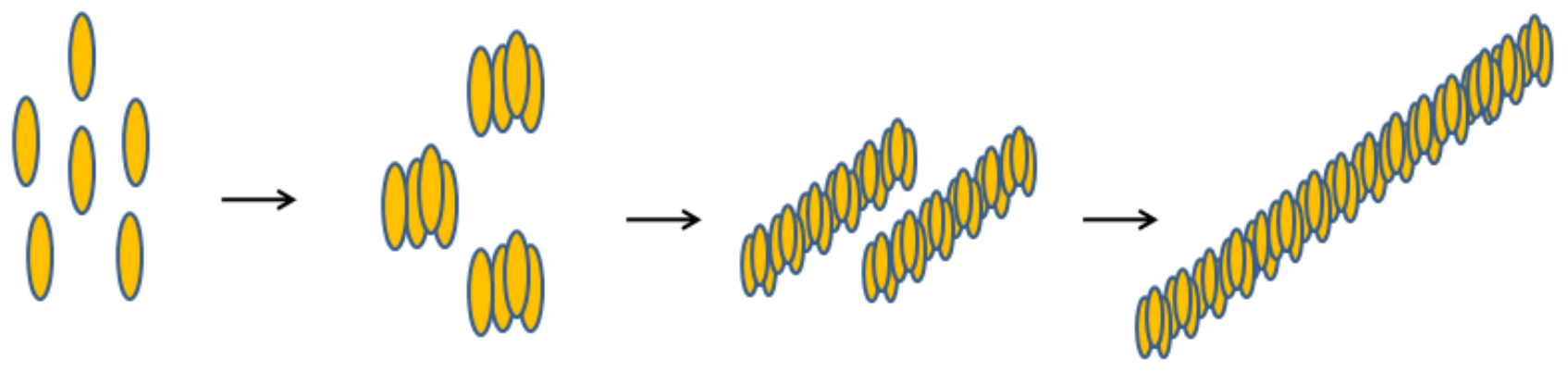

Figure 1 - A commonly studied A $\beta 40$ aggregation pathway. 


\subsection{Definition of Various A $\beta 40$ Aggregated Conformers}

In order to properly interpret $\mathrm{A} \beta 40$ fibril remodeling/structural changes induced by small molecules, concrete definitions of the various possible $A \beta 40$ protein aggregate species are needed. Disordered aggregates, protofibrils, and amyloid fibrils were introduced as three general categories of conformers that can be sampled during the A $\beta 40$ aggregation pathway discussed in Section 1.1. Therefore, it is important to establish structural criteria (i.e. data endpoints from commonly used techniques) for each of these three conformers.

Listed below are the expected data endpoints from several commonly-used assays (background on assays will be discussed in detail in the following section) based on reports in the literature for the three conformers:

\subsubsection{Disordered Aggregates}

- Thioflavin $T$ (ThT) - ThT negative. ${ }^{25,26}$ Not applicable if studying samples containing spectrophotometrically active small molecules. ${ }^{1}$

- Dot Blotting with OC Antibody - OC negative. ${ }^{27}$ Must be careful interpreting results due to possible false negative signals due to small molecule binding. ${ }^{1}$

- Morphology using Transmission Electron Microscopy (TEM)/Atomic Force Microscopy (AFM) - Amorphous aggregates with varying sizes/morphologies lacking defined, persistent morphological features. ${ }^{21,25,28-30}$

- Secondary Structure using Circular Dichroism (CD) - Random coil/disordered secondary structure CD spectra. ${ }^{31-35}$ 


\subsubsection{Protofibrils}

- $T h T$ - Moderately ThT positive. ${ }^{32,} 36$ Not applicable if studying samples containing spectrophotometrically active small molecules. ${ }^{1}$

- Dot Blotting with OC Antibody - OC positive. ${ }^{27}$ Must be careful interpreting results due to possible false negative signals due to small molecule binding. ${ }^{1}$

- Morphology using TEM/AFM - Shorter, filamentous, rod-like aggregate with visible defined and persistent structure. Length $<400 \mathrm{~nm} .{ }^{37}$ Width $\sim 12 \mathrm{~nm} .{ }^{38}$

- Secondary Structure using $C D$ - $\beta$-sheet secondary structure CD spectra. ${ }^{31-34}$

\subsubsection{Fibrils}

- $T h T$ - Strongly ThT positive. ${ }^{35,} 39-42$ Not applicable if studying samples containing spectrophotometrically active small molecules. ${ }^{1}$

- Dot Blotting with OC Antibody - OC positive. ${ }^{27}$ Must be careful interpreting results due to possible false negative signals due to small molecule binding. ${ }^{1}$

- Morphology using TEM/AFM - Long, filamentous, rod-like aggregate with visible defined and persistent structure. ${ }^{43}$ Length $\sim 1 \mu \mathrm{m} .{ }^{43}$ Width $\sim 20 \mathrm{~nm}^{38,44}$

- Secondary Structure using $C D$ - $\beta$-sheet secondary structure CD spectra. ${ }^{31-34}$ 


\section{Background and Theoretical Development}

Protein misfolding and aggregation have attracted great attention in recent years. These phenomena are implicated in the onset of numerous human diseases. Misfolding and aggregation of proteins are known to cause numerous neurodegenerative diseases, such as Alzheimer's disease (AD), Parkinson's disease (PD), and Huntington's disease. ${ }^{45-50} \mathrm{AD}$ is the most common form of dementia. Currently, 5.3 million people in US are affected, with the number projected to rise to 13.5 million by $2050 .^{51} \mathrm{PD}$ is the second most common neurodegenerative disease, with nearly 1 million people in the US affected. PD is a brain disorder leading to shaking and difficulty with walking and movement.

A common pathological hallmark of these neurodegenerative diseases is the accumulation of insoluble protein aggregates in the central nervous system. AD and PD are closely associated with aggregation of toxic amyloid-beta peptide $(\mathrm{A} \beta)$ and $\alpha$-synuclein, respectively. $A \beta$ and $\alpha$-synuclein are accumulated outside of the cells. ${ }^{52,53}$ Therefore, monitoring protein aggregation in vitro is an appropriate and cost-efficient first step to understanding the molecular mechanism of these neurodegenerative diseases and in identifying drug candidates capable of modulating protein aggregation before studying the action in animals or humans.

Because of the importance and complexities of in vitro monitoring techniques in the study of protein aggregation/neurodegenerative diseases, it was necessary to have a good fundamental knowledge of the techniques available prior to beginning our experiments using $A \beta 40$.

\subsection{Monitoring Protein Aggregation In Vitro ${ }^{6}$}

Partially misfolded or misfolded proteins self-assemble to form protein aggregates in vitro. Protein aggregates in general have diverse structures, including disordered aggregates, prefibrillar aggregates, and amyloid fibrils (Figure 2). Originally, insoluble fibrils were thought to be the principal 
conformer conferring neurotoxicity in diseases such as $\mathrm{AD}^{2}$ As such, the scientific community committed much time and resources into the development and optimization of many "traditional" in vitro techniques to characterize this particular form of protein aggregate. However, through recent in vivo and in vitro discovery, smaller, prefibrillar aggregates (Figure 2) have now emerged as the primary toxic species in several of these diseases. ${ }^{54-57}$ Prefibrillar aggregates include the following conformers: prefibrillar oligomers (globular aggregates lacking the ordered cross-stacked $\beta$-sheet structure) and fibrillar oligomers/protofibrils (aggregates with the cross-stacked $\beta$-sheet structure). Because of this paradigm shift, many limitations and potential drawbacks of using "traditional" fibril monitoring techniques to study prefibrillar aggregates have become apparent. In addition, new techniques (or new uses of "traditional" techniques) have emerged to better characterize prefibrillar/oligomeric aggregates and the effectiveness of proposed aggregation inhibition therapies. The focus of this section is to review recent trends in the use of several "traditional" techniques (small molecule probes, TEM/AFM, and $\mathrm{CD} /$ FTIR) and a new technique (dot-blot assay using conformational-specific antibodies) for routine in vitro monitoring of protein aggregation.

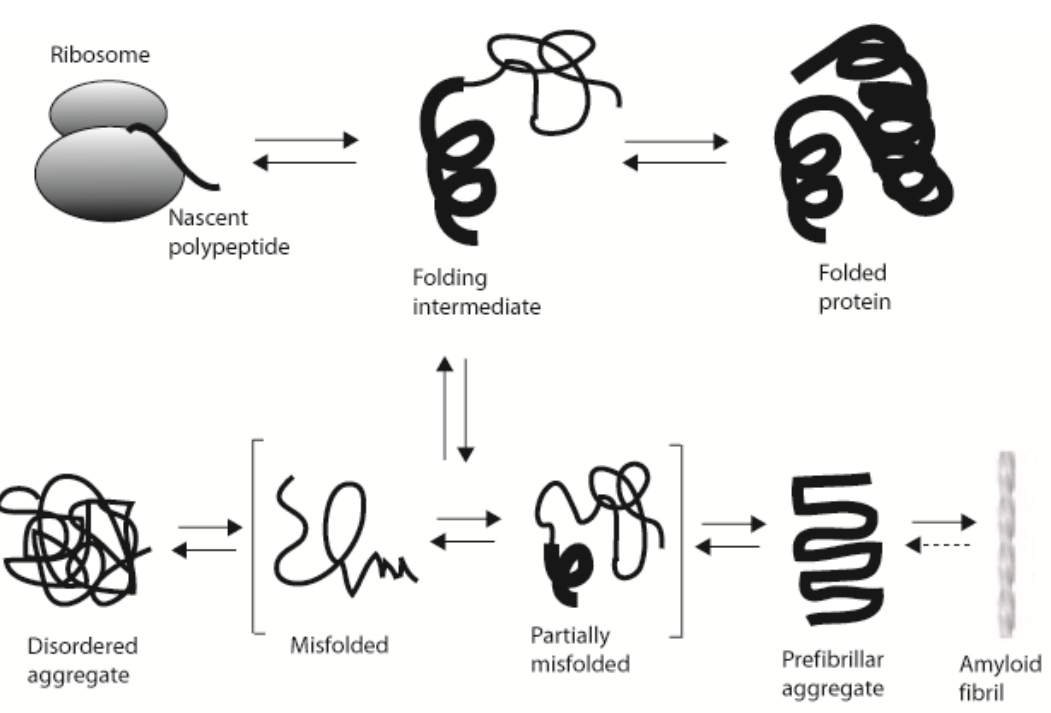

Figure 2. General scheme of protein folding and misfolding/aggregation. 


\subsubsection{Molecular Probes for Aggregate Characterization}

\subsubsection{Thioflavin T Binding Assay}

The use of a small molecule dye, Thioflavin T (ThT), and its derivatives is arguably the simplest and most widely used method to monitor aggregation of amyloidogenic proteins. ThT displays a fluorescence emission maximum at around the $485 \mathrm{~nm}$ wavelength upon binding to the $\beta$-sheet groove structure of fibrillar protein aggregates. ${ }^{58}$ The use, binding sites, and binding mechanisms of ThT with protein aggregates have been reviewed extensively. ${ }^{36,59-65}$

Traditionally, ThT has been used to detect amyloid fibrils only due to the characteristic sigmoidal increase in fluorescence that occurs between the monomer and end fibril state. $1,35,39-42$ However, ThT has also been found to bind prefibrillar aggregates that contain the $\beta$-sheet groove binding site (fibrillar oligomers and protofibrils). Prefibrillar aggregates which contain the $\beta$-sheet structure have fewer binding sites than fibrils and so their fluorescence is lower, but still observable (1.5 fold increase for prefibrillar aggregates vs. 100 fold for fibrils). ${ }^{32,36}$ Therefore, ThT signal can prove indicative to the presence of toxic protofibrils and fibrillar oligomers, but not prefibrillar oligomers that lack defined $\beta$-sheet structure. ${ }^{25,26}$ Lastly, caution should be taken when using ThT to monitor aggregation in the presence of aggregation inhibitors due to potential spectral interference with ThT fluorescence. ${ }^{1,6,39,62}$

Because small molecule modulators were being studied in this thesis work, ThT fluorescence was used to verify fibril formation in the absence of any small molecule, but could not be used to investigate the remodeling effect once the small molecules were applied due to spectral interference issues. 


\subsubsection{Congo Red Binding Assay}

Congo Red (CR) is another small molecule probe which, similar to ThT, has traditionally been used to identify amyloid fibrils, specifically in the form of deposits in the brain tissue or in vitro (reviewed in $36,59,61,66$ ). CR binds to $\beta$-sheet rich structures present in amyloid fibrils ${ }^{62}$ and demonstrates a characteristic shift in the absorbance maximum from 490 to $540 \mathrm{~nm}$ and green birefringence with crossed polarized light. ${ }^{60}$

More recent studies have shed light on the use of CR toward examining prefibrillar aggregates. Walsh et al. observed a change in $\mathrm{CR}$ absorbance when applied to protofibrils, albeit the change was less marked than that of amyloid fibrils. ${ }^{67}$ Additionally, Maezawa et al. applied surface plasmon resonance to identify the binding affinity/dissociation constant of CR towards prefibrillar oligomers. ${ }^{61}$ However, a shift in absorbance maximum upon CR binding was not observed for prefibrillar oligomers. So, as was the case with ThT, recent studies demonstrate that CR could be applicable to characterize protofibrils, fibrils, and fibrillar oligomers, but not prefibrillar oligomers that do not have defined stacked $\beta$-sheet structure.

Because CR binding yields similar information as that obtained from ThT fluorescence, it was not needed in the thesis work to verify fibril formation.

\subsubsection{Antibody Dot Blot Assay}

Because of the difficulty in obtaining high resolution crystal structures of protein aggregates (prefibrillar aggregates, in particular), conformational-specific antibodies have been developed over the past 10 years to help identify and monitor the state of amyloidogenic protein aggregation and screen potential aggregation inhibitors/modulators.

Glabe et al. developed three conformational-specific antibodies that are important to detect physiologically-relevant prefibrillar aggregates: A11 (recognizing prefibrillar oligomers but not fibrillar 
conformers ${ }^{54} \mathrm{OC}$ (recognizing the cross-stacked $\beta$-sheet structure of fibrillar oligomers, protofibrils, and fibrils $;{ }^{27}$ and $\alpha \mathrm{APF}$ (recognizing annular protofibrils ${ }^{33}$ ). These conformational-specific antibodies have been extensively used and reviewed..$^{24,34,35,55,61,68}$

Even though the application of these antibodies has provided important insight into the properties of protein aggregates and the effects of potential therapeutics, recent studies have shown that care must be taken when using and interpreting the results. First, due to the transient nature of prefibrillar aggregates compared to end-state conformers, preparing a homogeneous sample of exclusively A11, OC, or aAPF reactive (no cross reactivity) aggregates in vitro has proven quite challenging, though preparation of homogeneous prefibrillar aggregates were reported by a few research groups. ${ }^{25,32,33}$ Despite their success, non-physiological aggregation conditions (low $\mathrm{pH}^{32}$ ) or incomplete removal of pre-treatment disaggregation agent ${ }^{25}, 32$ were employed in order to generate these homogeneous populations. Other groups who have applied the OC and A11 conformational-specific antibodies have observed more non-homogeneous populations, either in the form of fibrillar conformers populations containing significant A11-reactivity ${ }^{69-71}$ or prefibrillar oligomer populations possessing significant OC-reactivity. ${ }^{39,72}$ Because of the cross reactivity demonstrated by these populations, it is difficult to discern which species is dominant. Second, in rare but present cases, ${ }^{73}$ false positive antibody reactivity has been observed when testing the inhibitory/modulatory activity of extrinsic compounds on protein aggregates. Third, binding of these extrinsic compounds to antibody epitopes on protein aggregates can block subsequent antibody binding, ${ }^{1}$ leading the investigator to think that significant and rapid conformational changes have occurred, when in reality, they may not have. Because of these three factors, care must be taken when designing experiments and interpreting the results of these antibodies.

Because of the insight that the three primary conformational-specific antibodies discussed above have given and due to the high degree of polymorphism that exists in prefibrillar aggregates, additional conformational-dependent antibodies are being developed to further characterize these conformers. 
Wang et al. developed four single-chain variable fragment antibodies that specifically recognize $A \beta$ oligomers, but not monomers or fibrils. ${ }^{74}$ However, the use of this antibody does not appear to have caught on in a widespread manner throughout the community. Furthermore, Kayed et al. developed 6 new monoclonal antibodies that recognize immunologically distinct preparations and sub-variants of prefibrillar oligomers also recognized by the more general polyclonal antibody, A11. ${ }^{75}$ Even though the sub-classes of prefibrillar oligomers identified by the monoclonal antibodies showed different molecular weight size distributions through Western blot analysis, it is not yet clear whether or not these variants are more pathologically relevant than A11 antibody.

Because this thesis work focuses on changes from the amyloid fibril state, the primary conformationally-specific antibody used was OC.

\subsubsection{Methods for Obtaining Visual Morphological (Quaternary Structure) Information on Protein Aggregate Species}

\subsubsection{Electron Microscopy \& Atomic Force Microscopy}

Transmission Electron Microscopy (TEM) and Atomic Force Microscopy (AFM) are the two techniques most commonly used to visualize the morphology of amyloidogenic protein aggregate samples. $^{32,35,39,41,42,61,62,70,72,76-81}$ Both TEM and AFM provide information (both qualitative and quantitative) at the nanometer level of quaternary structure characteristics, including the length, width, curvature, and surface features of protein aggregates (reviewed in 59, 65, 82-86).

However, there are several significant differences and/or limitations to consider when using these methods to study protein aggregates. Although TEM has the advantage of being a direct method (i.e. crystallization of the sample is not required ${ }^{82}$ ) and can be performed fairly quickly, ${ }^{84}$ the detection limit for smaller aggregates less than $\sim 20 \mathrm{~nm}$ is fairly limited compared to higher resolution techniques, 
such as AFM. ${ }^{1,86}$ Because of this limitation, TEM is generally accepted as being useful in verifying formation, inhibition, and/or disaggregation of larger protofibrils/fibrils and providing an approximate gauge for morphology of smaller aggregates, but not as the sole source for yielding high-resolution, low-error details of small prefibrillar conformers. However, it is important to note that despite this drawback, TEM has been used to provide a numerical estimation of the length or width of smaller aggregates less than $30 \mathrm{~nm}^{26,72,87}$

Conversely, AFM provides sub-nanometer three-dimensional (including height) detection of protein sample characteristics ${ }^{88}$ and is thus well-suited for studying smaller prefibrillar aggregates with low expected error. However, the sample preparation for AFM often takes longer and involves more steps (for example, freezing or adsorption to mica surface) than a simple negative-stain TEM sample preparation $^{84}$. In addition, some convolution of the data is introduced when the radius of curvature of the tip used is close to the dimensions of the aggregates being studied. ${ }^{1,89}$

Because AFM and TEM are such complimentary techniques (each with their respective strengths and weaknesses), both were used in this thesis work.

\subsubsection{Methods for Obtaining Secondary Structure Information on Protein Aggregate Species}

\subsubsection{Circular Dichroism \& Fourier Transform Infrared Spectroscopy}

Circular Dichroism (CD) and Fourier Transform Infrared Spectroscopy (FTIR) are two wellestablished techniques that are used most frequently to assay the secondary structure ( $\beta$-sheet, $\alpha$-helix, $\beta$-turn, and disordered content) of protein aggregates in vitro. ${ }^{40,41,80,81} \mathrm{CD}$ measures the differential absorption of right and left polarized light, and FTIR analyzes molecular bond vibration frequencies. ${ }^{85}$ Although it has been reported to be theoretically possible to determine antiparallel vs. parallel $\beta$-sheet 
secondary structure using $\mathrm{CD},{ }^{90,}{ }^{91}$ FTIR is used more readily to obtain resolution on secondary structures within the $\beta$-sheet group.

Secondary structure content is important for the study of protein aggregates because specific secondary structures are characteristic of different stages in the aggregation pathways. For example, in the $\mathrm{A} \beta$ peptide associated with $\mathrm{AD}$, monomers and small oligomers have been found to consist of mainly unordered $/ \alpha$-helical structures, whereas the intermediate fibrillar oligomers, protofibril, annular protofibril, and ending fibril conformers contain mostly $\beta$-sheet secondary structure. ${ }^{31-34}$ Unlike the other conformers, there is a considerable amount of disagreement in the literature regarding the secondary structure of soluble prefibrillar oligomers. On one hand, several research groups have reported that $\mathrm{A} \beta$ oligomers contain mostly random coil/disordered secondary structure, ${ }^{25,26}$ while others have reported these oligomers possessing prevailing parallel or antiparallel $\beta$-sheet content. ${ }^{69,70,87}$ Given the transient nature of this aggregate species and the difficulty in preparing a homogeneous conformer sample, it is not surprising that different research labs obtained different results.

Despite extensive general reviews of the techniques ${ }^{59,65,85,86,92-94}$ and the vast amount of primary works employing CD and FTIR to assess protein aggregates, a single, straight-forward protocol does not exist that details how to use these methods to estimate secondary structure content percentages. Instead, researchers employ a milieu of scientifically acceptable approaches to estimate secondary structure content from the raw CD and FTIR data generated. Often, a qualitative-based analysis is used by comparing general features of the CD or FTIR spectra with controls or "expected" results, which are used to correlate secondary structure changes or overall content. For example, the CD or FTIR spectra of an unknown protein aggregate sample could be compared to a predominantly $\beta$-sheet fibril control spectra, and deviations could be visualized. ${ }^{32}$ Similarly, spectral features of an unknown sample, such as curve minima and maxima between 190-250 $\mathrm{nm}$ for CD and 1600-1700 $\mathrm{cm}^{-1}$ for FTIR are often compared to established "expected" correlations to obtain a qualitative assessment of the major secondary structure features. ${ }^{25,71,72,78}$ Correlations of CD and FTIR curve characteristics to secondary 
structure have been reviewed. ${ }^{59,95}$ Alternatively, a more complex, but quantitative analysis has been developed and utilized in order to estimate the percentage of secondary structure content of a sample from $\mathrm{CD}$ spectral data using one or more single value decomposition, regression, or neural network algorithms available. ${ }^{96-98}$ Several examples of these methods/algorithms include CDSSTR, SELCON, CONTIN, and K2D. ${ }^{99}$ It is important to note that the majority of these algorithms require that the sample CD spectra is 'matched' to a protein with known secondary structure content within various protein reference sets. ${ }^{95}$ Because amyloidogenic proteins (or their parent proteins) and disordered/random coil proteins are often not included in these reference sets, caution should be taken in interpreting CD spectra of disordered prefibrillar aggregates. ${ }^{1,6}$ Additionally, the numerical results obtained from the analysis should agree (at least directionally) with what is seen upon visual inspection of the sample spectra, and the error value (normalized root mean square deviation) should not be the only criteria used to select the best fit. Lastly, care must be taken to ensure the CD cuvette is sufficiently cleaned and dried prior to reading each sample. Cleaning often needs to be done with a solvent other than water, such as $2 \%$ Helmanex Solution. To ensure the cuvette is sufficiently clean, it is advisable to run a dd $\mathrm{H}_{2} \mathrm{O}$ baseline prior to every protein aggregate sample to confirm drift has not occurred.

Due to equipment accessibility and the fact that resolution within the $\beta$-sheet secondary structure group was not needed (through FTIR), CD analysis was used in this thesis work. 


\section{Research Scope and Objectives}

\subsection{Research Scope}

The scope of this thesis work was to perform comparative in vitro studies on the structural features of the different $A \beta$ aggregates converted from $A \beta 40$ amyloid fibrils destabilized by three exogenous biocompatible small molecules.

The three small molecules chosen were methylene blue (MB), brilliant blue $\mathrm{G}(\mathrm{BBG})$, and erythrosine B (ER) (Figure 3), due to their favorable features for our studies. ${ }^{1}$ First, these three molecules are effective modulators of $A \beta$ aggregation and cytotoxicity. Our research group recently reported that red food dye (ER) and the blue food dye analog (BBG) are novel small-molecule modulators of $A \beta 40$ monomer aggregation and effectively eliminate $A \beta$-associated cytotoxicity by promoting non-toxic $A \beta$ aggregate formation but reducing toxic $A \beta$ aggregate formation. ${ }^{39,}{ }^{100} \mathrm{MB}$ has also been shown to modulate $A \beta 42$ aggregation and cytotoxicity by promoting less toxic amyloid fibril formation but preventing the formation of very toxic prefibrillar oligomers. ${ }^{35,101}$ Therefore, it was expected that these three molecules will interact with A $\beta 40$ fibrils despite the lack of previous evidence. Second, MB, BBG, and ER are structurally quite distinct, representing phenothiazine, triphenylmethane, and xanthene benzoate groups, respectively. Therefore, these three molecules most likely have different interaction modes on $\mathrm{A} \beta 40$ fibrils. Third, these three molecules have good potential for therapeutic application since they are safe, biocompatible, and potentially blood-brain barrier permeable. ${ }^{102-114} \mathrm{MB}$ has already been shown to have a wide variety of medicinal applications, including treatment of malaria and cancer. ${ }^{115-117}$ Furthermore, the Phase II clinical trials of MB on AD demonstrated promising results. ${ }^{118}$ BBG expedited the recovery after spinal cord injury and conferred neuroprotection to the brain by mitigating $\mathrm{AD}$ and multiple sclerosis symptoms. ${ }^{110,113,114}$ ER is a Food and Drug Administration-approved red food coloring dye. A daily dose up to $60 \mathrm{mg} / \mathrm{kg}$ of ER is non-toxic to humans. ${ }^{107}$ These three compounds are either being taken or might be taken in the future by humans. Since testing small molecules in vivo is not trivial, in vitro studies on the effects of these three 
molecules on amyloid fibrils will serve a good reference to gauge their destabilizing capacity on the amyloid fibrils in the human brain.

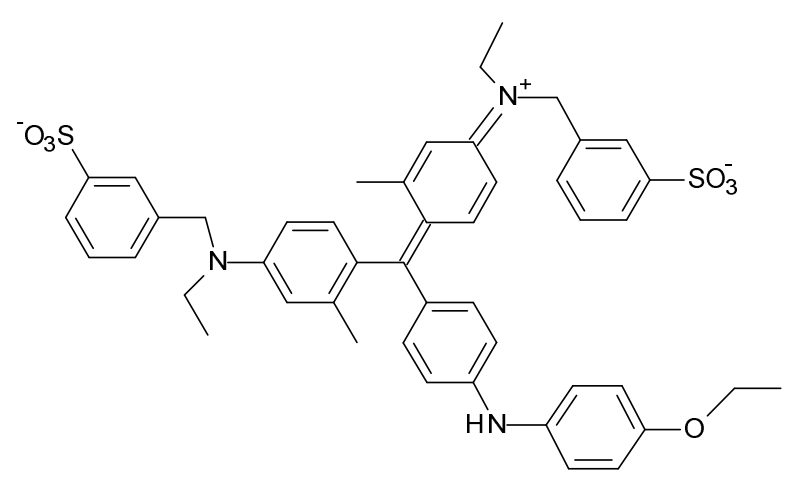

Brilliant Blue G (BBG)

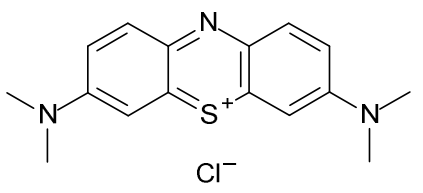

Methylene Blue (MB)

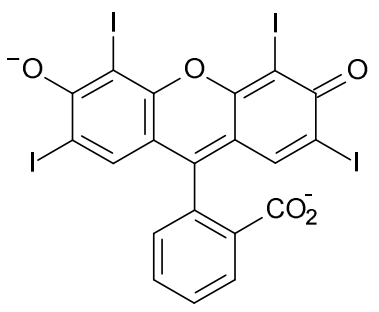

Erythrosine B (ER)

Figure 3. Chemical structure of brilliant blue G (BBG), methylene blue (MB), and erythrosine $\mathrm{B}(\mathrm{ER})$ at neutral $\mathrm{pH}$. 


\subsection{Research Objectives}

The purpose of this thesis work was to perform comparative in vitro studies on the structural features of the different $A \beta$ aggregates converted from $A \beta 40$ amyloid fibrils destabilized by three exogenous biocompatible small molecules, methylene blue (MB), brilliant blue G (BBG), and erythrosine B (ER). The following objectives were completed in order to investigate and classify these changes.

1. Assess morphology of the remodeled A $\beta$ aggregates using TEM and AFM.

a. If aggregates have a persistent, defined structure, assess average length and thickness.

b. Compare morphological characteristics to untreated $A \beta$ fibril control.

2. Assess secondary structure of remodeled aggregates using CD spectra analysis.

a. Quantify secondary structure content using numerical deconvolution software platform.

b. Compare secondary structure content to untreated $A \beta$ fibril control.

3. Assess morphological changes and/or binding sites of the three small molecules using conformational and sequence-specific antibody dot blot analysis.

a. Propose mechanisms by which the small molecules trigger structural changes in the fibrils.

4. Classify remodeled A $\beta$ aggregates using the criteria for various $A \beta 40$ conformers discussed in Section 1.2. 


\section{Materials and Methods}

\subsection{Materials}

A 340 lyophilized powder was purchased from Selleck Chemicals (Houston, TX). Horseradish peroxidase (HRP)-conjugated goat anti-rabbit IgG antibody was obtained from Invitrogen (Carlsbad, CA). 4G8 antibody was obtained from Covance (Dedham, MA). Polyclonal OC and monoclonal 6e10 antibodies were obtained from Millipore (Billerica, MA). Nitrocellulose membranes and ECL Advance chemiluminescence detection kit was obtained from GE Healthcare Life Sciences (Waukesha, WI). Thioflavin T was purchased from Acros Organics (Geel, Belgium). All other chemicals were obtained from Sigma-Aldrich (St. Louis, MO) unless otherwise noted.

\subsection{Methods}

\subsubsection{A $\beta$ Fibril Formation and Remodeling.}

A $\beta 40$ fibrils were prepared by dissolving lyophilized A $\beta 40$ peptide powder from Selleck in $100 \% \mathrm{HFIP}$ at room temperature at a concentration of $1 \mathrm{mM} \mathrm{A} \beta 40$. After a 2 hour incubation period at room temperature, the HFIP was evaporated to dryness in a gentle stream of nitrogen gas. Then, the peptide was diluted to $50 \mu \mathrm{M} A \beta 40$ in phosphate buffered saline (1X PBS) solution (10 $\mathrm{mM} \mathrm{NaH}_{2} \mathrm{PO}_{4}$ and $150 \mathrm{mM} \mathrm{NaCl}$ at $\mathrm{pH} 7.4)$ and incubated for $10-13$ days at $37^{\circ} \mathrm{C}$ without stirring. To examine the remodeling effect of brilliant blue $\mathrm{G}(\mathrm{BBG})$, methylene blue (MB), and erythrosine $\mathrm{B}$ (ER), concentrated stock solutions of each small molecule dissolved in 1X PBS were added to the preformed A $\beta 40$ fibrils. The samples were then incubated for an additional 1 day at $37^{\circ} \mathrm{C}$ without stirring.

\subsubsection{Thioflavin T (ThT) Assay.}

ThT fluorescence assay was performed as reported previously. ${ }^{39,}{ }^{100} \mathrm{~A} \beta 40$ fibril formation was monitored by diluting $5 \mu \mathrm{L}$ of $50 \mu \mathrm{M} A \beta$ sample solution in $250 \mu \mathrm{L}$ of $10 \mu \mathrm{M}$ ThT in black 96 -well 
plates (Fisher Scientific, Pittsburgh, PA). The resulting ThT fluorescence of the A $\beta$ sample was measured at an emission wavelength of $485 \mathrm{~nm}$ using an excitation wavelength of $438 \mathrm{~nm}$ in a Synergy $4 \mathrm{UV}-\mathrm{Vis} /$ fluorescence multi-mode microplate reader (Biotek, VT).

\subsubsection{Transmission Electron Microscopy (TEM).}

Aggregate morphology was assessed using TEM and was performed as reported previously. ${ }^{39,100}$ A $\beta$ samples $(10 \mu \mathrm{L}$ of $50 \mu \mathrm{M} \mathrm{A} \beta)$ were placed on 200 mesh formvar coated/copper grids (Electron Microscopy Sciences, Hatfield, PA), adsorbed for 1 minute, and blotted dry with filter paper. Grids were then negatively stained for 45 seconds with 2\% uranyl acetate solution (Electron Microscopy Sciences, Hatfield, PA) in doubly distilled water $\left(\mathrm{ddH}_{2} 0\right)$, blotted dry, and then inspected with a JEOL 1010 Transmission Electron Microscope operated at $60 \mathrm{kV}$. Aggregate length and width was then quantified where appropriate using Image J software (NIH).

\subsubsection{Atomic Force Microscopy (AFM).}

$10 \mu \mathrm{L}$ of $\mathrm{A} \beta$ samples (diluted to $25 \mu \mathrm{M} \mathrm{A} \beta$ in molecular grade $\mathrm{ddH}_{2} 0$ ) were spotted on freshly cleaved V1 grade muscovite mica (Electron Microscopy Sciences, Hatfield, PA) and allowed to adsorb for 10 minutes. After adsorption, the samples were washed four times with $30 \mu \mathrm{L}$ molecular grade $\mathrm{ddH}_{2} \mathrm{O}$ to remove residual salts, dried with a gentle stream of pure nitrogen gas, and placed in a covered petri dish to dry completely overnight. Dry AFM images were taken using an NT-MDT Solver Pro M system with NSG01 silicon cantilevers (NT-MDT, Santa Clara, CA, guaranteed $<10$ nm radius of curvature, $5.1 \mathrm{~N} / \mathrm{m}$ force constant) in semi-contact mode. Aggregate length and width was then quantified where appropriate using the Gwyddion SPM analysis software package. ${ }^{119}$

\subsubsection{Circular Dichroism (CD) and Numerical Spectra Deconvolution.}

The secondary structure of $A \beta$ aggregates was evaluated using a Jasco 710 spectropolarimeter (1-mm path length quartz cuvette) at room temperature by diluting $30 \mu \mathrm{L}$ of $50 \mu \mathrm{M} A \beta$ sample in 270 
$\mu \mathrm{L}$ of $\mathrm{ddH}_{2} \mathrm{O}$ (1:10 dilution). The background contribution of the $1 \mathrm{X}$ PBS solvent and an appropriate small molecule (BBG, MB, or ER) was then carefully subtracted to obtain the spectra plots displayed. Each background-subtracted sample spectra is the average of at least 10 readings. The backgroundsubtracted sample spectra was then deconvoluted to obtain numerical estimations of secondary structure content using the DichroWeb online circular dichroism analysis software server, ${ }^{91}$ employing the CONTINLL analysis program ${ }^{120,121}$ along with 'Set \#6, ${ }^{, 22,123}$ or the $\mathrm{SP} 175^{124}$ reference sets in DichroWeb.

\subsubsection{Antibody Dot-Blot Assay.}

Dot-blot assays were performed as reported previously. ${ }^{39,100} 2 \mu \mathrm{L}$ of $50 \mu \mathrm{M} \mathrm{A} \beta$ samples were loaded on nitrocellulose membranes at the desired time points during fibril destabilization, allowed to air dry, and then were stored at $4{ }^{\circ} \mathrm{C}$ until immunostaining. For immunostaining, nitrocellulose membranes were first blocked for 1 hour in 5\% skim milk dissolved in Tris-buffered saline solution with $0.1 \%$ Tween 20 (Bio-Rad, Hercules, CA) (1X TBS-T - 0.05 M Tris base, 0.15 M NaCl, pH 7.44). Membranes were then exposed to three, 5 minute washes with $1 \mathrm{X}$ TBS-T. Next, the membranes were incubated for 1 hour with OC (1:14,000 dilution), 6E10 (1:14,000 dilution), or 4G8 (1:7,000 dilution) primary antibody diluted to the specified factor in $0.5 \%$ milk $1 \mathrm{X}$ TBS-T solution. After the incubation, membranes were then again exposed to three, 5 minute washes with $1 \mathrm{X}$ TBS-T. The dot blot intensity of the membrane immuno-stained with 4G8 antibody (already has horseradish peroxidase conjugated) was visualized by exposing the membrane to the ECL substrate (ECL Advance Detection Kit - GE Healthcare) and then imaged in a BioSpectrum imaging system (UVP, Upland, CA). The membranes immunostained with $\mathrm{OC}$ and 6E10 antibodies were incubated for 1 hour with HRP-conjugated goatanti-rabbit IgG secondary antibody at a $1: 10,000$ dilution in $0.5 \%$ milk $1 \mathrm{X}$ TBS-T and then visualized using the ECL substrate as described for the 4G8 membrane. 


\section{Results and Discussion}

\subsection{BBG Fragments Preformed A $\beta$ Fibrils.}

$\mathrm{A} \beta$ fibrils were prepared by incubating A $\beta 40$ monomers for 10 to 13 days. Thioflavin $\mathrm{T}$ (ThT) fluorescence, transmission electron microscopy (TEM), and circular dichroism (CD) assays were employed to verify the formation A $\beta$ fibrils. ThT binding and its resulting fluorescence is widely used to monitor fibril formation. ${ }^{6}$ The initiation of fibril assembly is characterized by a sharp increase in ThT fluorescence, while mature fibrils are predominantly present when the emission signal reaches a maximum and plateaus. Consequently, A $\beta$ fibril assembly as measured by ThT fluorescence can be modeled by sigmoidal regression. The ThT fluorescence curve in Figure S1 exhibits this behavior. Fibril formation commences on day 5 and ThT fluorescence reaches a maximum by day 10 (Figure S1 in Supporting Information - Section 9). Furthermore, from day 9 to day 10, there is no significant increase in ThT fluorescence. Next, TEM was utilized to visually verify the presence of fibrils (Figure 4A; Panel $\mathrm{A} \beta$ only and Figure S2 Panel A $\beta$ only for wider frame in Supporting Information - Section 9). Consequently, both ThT fluorescence and TEM results verify that fibrils are present. Next, CD was employed to characterize the secondary structure of the fibrils. The $\mathrm{CD}$ spectrum of the A $\beta$ fibrils exhibited the typical features of $\beta$-sheet structures (Figure 4C) supporting the fibrillar structure formation. $^{6}$

Next, we investigated whether BBG can destabilize preformed fibrils and generate different forms of aggregates using transmission electron microscopy (TEM), atomic force microscopy (AFM), circular dichroism (CD), and dot-blot assays with A $\beta$-specific antibodies. Although measuring ThT fluorescence intensity has also been used to monitor a loss of $A \beta$ fibrils, we could not employ this method in our studies due to the reported spectral interference of small molecules, including curcumin,

BBG, and ER on ThT fluorescence measurement. $6,39,62,100$ The preformed A $\beta$ fibrils were then 
incubated in the absence or presence of BBG for 1 day. First, both the A $\beta$ fibrils and the BBG-treated $\mathrm{A} \beta$ fibrils were subjected to negative-stain TEM analysis. The A $\beta$ fibrils exhibited the typical morphological features of amyloid fibrils (Figure 4A; Panel A $\beta$ only and Figure S2; Panel A $\beta$ only for wider frame in Supporting Information - Section 9) - long, filamentous, and rod-like with defined and persistent structure. The length of the $A \beta$ fibril population was measured and found to have an average length of $1,026 \pm 621 \mathrm{~nm}$, consistent with the fibril criteria established in Section 1.2.3. The population of the fibrils with a length greater than $1,100 \mathrm{~nm}$ is $35 \%$ (Table $1 \mathrm{~A}$ ). In contrast, BBG treatment generated much shorter, rod-like (with defined structure) aggregates of average length $133 \pm 65 \mathrm{~nm}$ (Figure 4A; Panel BBG and Figure S2: Panel BBG for wider frame in Supporting Information - Section 9; Table 1A). Although only $6 \%$ of the untreated A $\beta$ fibrils have a length less than $300 \mathrm{~nm}, 97 \%$ of the BBG-treated A $\beta$ aggregates have a length less than $300 \mathrm{~nm}$ (Table 1A), indicating that the BBG-treated $A \beta$ aggregates were strikingly shorter than the untreated $A \beta$ fibrils. Next, we investigated the morphological trends of the remodeled fibrils observed using AFM. As was the case with the TEM results, most of the untreated $\mathrm{A} \beta$ fibrils are intermingled (Figure $4 \mathrm{~B}$; Panel $\mathrm{A} \beta$ only), while treatment with 10X BBG resulted in much shorter, dispersed aggregates (Figure 4B: Panel BBG). The lengths and widths of the two A $\beta$ samples were measured using the AFM image analysis software Gwyddion ${ }^{119}$ (Table S1A and S1B in the Supporting Information - Section 9). When we first began the AFM analysis of our samples, we expected to be able to directly compare the lengths and widths found with AFM to our TEM results. However, since the intrinsic resolution limit of AFM set by cantilever tip radius affects the absolute values of both lateral and height measurements ${ }^{89,125,126}$ and the detection limit of AFM is smaller than that of TEM, ${ }^{86,88}$ a direct comparison between TEM and AFM values was not possible. Therefore, we focused on comparing the length and width distribution trends between samples obtained using the two different microscopic assays. The average length of the 10X BBG-treated fibrils measured using AFM was $96 \pm 40 \mathrm{~nm}$, while the average length of the untreated A $\beta$ fibrils was much longer at $329 \pm 161 \mathrm{~nm}$, consistent with the remodeling trend observed in the TEM images. In fact, $88 \%$ of the BBG-treated sample had a length less than $150 \mathrm{~nm}$, while only $17 \%$ of the amyloid fibril sample had a 
length less than $150 \mathrm{~nm}$ (Table S1A in the Supporting Information - Section 9). A decrease in the average lengths of both the untreated and the BBG-treated A $\beta$ fibrils in AFM compared to TEM is likely due to the lower detection limit of AFM than that of TEM. In the TEM results, the percentages of the $A \beta$ aggregates of a length less than $200 \mathrm{~nm}$ are $2 \%$ and $88 \%$ for the untreated and the BBG-treated A $\beta$ fibrils, respectively (Table 1A). However, in AFM results, these values are 30\% and 98\% (Table S1A in the Supporting Information - Section 9), indicating that small A $\beta$ aggregates were better detected by AFM than TEM resulting in the decrease in the average length in AFM compared to TEM. Despite the differences in absolute average lengths, both the TEM and AFM results strongly support the idea that the BBG-treatment substantially reduces the average length of $A \beta$ fibrils. Therefore, the smaller, rod-like BBG-treated A $\beta$ aggregates could be protofibrils or fibril fragments.

In order to determine whether the BBG-treated aggregates are protofibrils or fibril fragments, their thicknesses/widths were measured and compared to those of untreated A $\beta$ fibrils. According to the A $\beta$ fibril structural model proposed by Schmidt et. al through cryo-EM and mass-per-length analysis of $\mathrm{A} \beta 40$ fibrils and protofibrils, ${ }^{38}$ the thicknesses of the individual $\mathrm{A} \beta$ fibril and protofibril are around 20 $\mathrm{nm}$ and $12 \mathrm{~nm}$, respectively. Despite concern over the intrinsic resolution of the technique, negativestain TEM has been used numerous times in the literature by different research groups to provide numerical estimation of the length or width of aggregates less than $30 \mathrm{~nm} .{ }^{6,26,72,87}$ More specifically, Fandrich, et al. employed TEM to measure the widths of $A \beta 40$ fibrils and found the average width to be $20.6 \pm 2.8 \mathrm{~nm},{ }^{44}$ which is in good agreement with the cryo-EM findings. ${ }^{38}$ The untreated A $\beta$ fibrils in this study exhibited an average width of $19 \pm 4 \mathrm{~nm}$ upon examination of the magnified TEM image (Figure 4A; Panel A $\beta$ only_M), with $98 \%$ of the fibrils measured having a width greater than $12 \mathrm{~nm}$ (Table 1B). Upon examination of the magnified TEM image, thickness of the BBG-treated A $\beta$ aggregates seems similar to that of the untreated A $\beta$ fibrils (Figure 4A; Panel BBG_M). The average width of the BBG-treated $\mathrm{A} \beta$ aggregates is $26 \pm 7 \mathrm{~nm}$ (Table 1B). In particular, none of the aggregates measured have a width of $12 \mathrm{~nm}$ or less, clearly indicating that the BBG-treated $\mathrm{A} \beta$ aggregates are not protofibrils. Considering that the average width of the BBG-treated $\mathrm{A} \beta$ aggregates is comparable to that 
of the untreated $A \beta$ fibrils, the BBG-treated $A \beta$ aggregates are considered shorter $A \beta$ fibrils compared to the untreated $A \beta$ fibrils. The AFM results also show similar trends in the width of the A $\beta$ aggregates (Table S1B in the Supporting Information - Section 9). The average width of the BBG-treated sample was $58 \pm 14 \mathrm{~nm}$, and the untreated $A \beta$ fibril sample had an average width of $73 \pm 23 \mathrm{~nm}$. In comparing the width distributions of these two samples measured using AFM, it was found that $86 \%$ of the BBGtreated sample's aggregate widths fall within one standard deviation of the A $\beta$ fibril average width, indicating that these samples possess similar widths and confirming the trend found in the TEM analysis. An increase in the average width of the A $\beta$ aggregates obtained using AFM assay compared to those of TEM assay can be attributed to the intrinsic resolution limit set by cantilever tip radius leading to over-estimation (convolution) of nanostructure widths. ${ }^{89,} 125$ Because BBG-treatment resulted in shorter, rod-like aggregates but of similar thickness as A $\beta$ fibrils, it was hypothesized that the BBGinduced $A \beta$ aggregates are likely fragmented fibrils but not protofibrils, according to the structural criteria set forth in Section 1.2.

In order to confirm this hypothesis, we also performed CD analysis. CD analysis is widely used to analyze secondary structure content of proteins. ${ }^{6,22,31,127,128}$ The $\mathrm{CD}$ spectra of both the $\mathrm{A} \beta$ fibrils and the $\mathrm{BBG}$-treated $\mathrm{A} \beta$ fibrils are shown in Figure $4 \mathrm{C}$ along with that of $\mathrm{A} \beta$ monomers for comparison. In the $\mathrm{CD}$ spectrum of $\mathrm{A} \beta$ monomers, neither $\alpha$-helix nor $\beta$-sheet structural features were observed, strongly suggesting that $\mathrm{A} \beta$ monomers have disordered structure (Figure $4 \mathrm{C}$ ). However, the $\mathrm{CD}$ spectrum of the $\mathrm{A} \beta$ fibrils exhibited the typical features of $\beta$-sheet-rich structure, ${ }^{6}$ including a minimum at $217 \mathrm{~nm}$ (Figure 4C). The BBG-treated A $\beta$ fibrils maintained the typical features of $\beta$-sheet structure. The minimum ellipticity value of the BBG-treated A $\beta$ fibrils was observed at $217 \mathrm{~nm}$. The ellipticity of the BBG-treated A $\beta$ fibrils was positive below $200 \mathrm{~nm}$. In order to quantitatively investigate secondary structural changes caused by BBG treatment, we used the web-based server, DichroWeb, ${ }^{91}$ and calculated the secondary structure contents from the CD spectra using the CONTIN analysis program ${ }^{120,121}$ and SP175 reference protein set. ${ }^{91,124}$ The $\alpha$-helix, $\beta$-sheet, $\beta$-turn, and 
disordered structure content of the $\mathrm{A} \beta$ fibrils are $12.2 \%, 36.4 \%, 12.1 \%$, and 39.3\% (Table 2), respectively, which is consistent with the $A \beta$ fibril structural information that the $\mathrm{N}$-terminus 17 residues (residues $1-17$ ) are usually disordered and the 6 residues (residues 23-28) in the middle of $A \beta$ sequence form $\beta$-turn structure. ${ }^{26}$ Upon one day incubation of the $A \beta$ fibrils with $B B G$, the secondary structural content was only slightly changed, with the $\beta$-sheet content increasing by $8 \%$ but the disordered structure content decreasing by around 7\%. The $\beta$-sheet content of the BBG-treated A $\beta$ fibrils is comparable to that of the $A \beta$ fibril control, suggesting that the BBG-treated $A \beta$ fibrils also have fibrillar structures similar to the $\mathrm{A} \beta$ fibril control. Considering that the BBG-treated $\mathrm{A} \beta$ fibrils have persistent fibrillar structures in the TEM image, these results support the idea that the BBG-treated A $\beta$ aggregates are shorter $A \beta$ fibrils than the untreated $A \beta$ fibril control, likely $A \beta$ fibril fragments.

Dot-blot assays of the $\mathrm{A} \beta$ samples were also performed using three $\mathrm{A} \beta$-specific antibodies (OC, 4G8, and 6E10). Recently, dot-blotting with $\mathrm{A} \beta$-specific antibodies has been widely used to detect $\mathrm{A} \beta$ aggregates with different conformations. $6,25,27,32,54,129-131$ OC is a polyclonal antibody that recognizes fibrillar oligomers, protofibrils and fibrils but not monomer, prefibrillar oligomers, and disordered aggregates. $^{25,27} 4 \mathrm{G} 8$ is an $\mathrm{A} \beta$ sequence-specific monoclonal antibody, ${ }^{132-135}$ which binds to amino acids 17 to 24 of $\mathrm{A} \beta$. Lastly, $6 \mathrm{E} 10$ is a monoclonal antibody that recognizes residues $1-16$ of $\mathrm{A} \beta .^{27}$, ${ }^{70}$ Although both $4 \mathrm{G} 8$ and $6 \mathrm{E} 10$ were originally used to ensure the conservation of $\mathrm{A} \beta$ moieties, recent findings demonstrated that immuno-reactivities of these two antibodies can be affected by $A \beta$ conformational changes and small-molecule binding to their epitopes. ${ }^{39,70,100}$ In order to distinguish the immuno-reactivity changes caused by the small molecules binding to antibody epitopes (fast processes) from those made by $A \beta$ conformation changes (slow processes), we incubated the $A \beta$ fibrils with the small molecules for a very short time (less than $5 \mathrm{~min}$ ) and for a longer time (one day). Incubation of the $\mathrm{A} \beta$ fibrils with $1 \mathrm{x}$ BBG (molar concentration equal to that of $\mathrm{A} \beta$ peptide) did not alter the immunoreactivities of $\mathrm{A} \beta$ fibrils for all three antibodies (OC, 6E10, and 4G8), strongly indicating that there is no change in the content of fibrillar structure (Figure 5). The 6E10 and 4G8 immuno-reactivities of the 
BBG-treated fibril samples at both 5 minutes and 1 day were maintained when compared to the fibril sample, indicating that BBG did not significantly bind to the 1-16 and 17-24 residues of $A \beta$. It is noteworthy that $10 \mathrm{x}$ BBG (10 times the molar concentration of $\mathrm{A} \beta$ peptide) resulted in a significant reduction of the OC-reactivity after 1-day incubation (Figure 5; Panel 1-day incubation). However, such a reduction in the OC-reactivity of the 10x BBG-treated $\mathrm{A} \beta$ fibrils can be explained by BBG binding to the OC epitope rather than a loss of fibrillar structure. The short incubation of $A \beta$ fibrils with $10 x \mathrm{BBG}$ is not long enough to cause $A \beta$ conformational changes resulting in a significant reduction in the OCreactivity (Figure 5; Panel $<5 \mathrm{~min}$ ), indicating that $\mathrm{BBG}$ binds to the epitope thus restricting the access of the OC antibody. It was also reported that BBG binds to $\mathrm{A} \beta$ peptide in multiple sites. ${ }^{100}$ Therefore, we speculate that direct binding of $B B G$ to $A \beta$ fibrils leads to $A \beta$ fibril fragmentation. ${ }^{1}$ Unlike $A \beta$ sequence specific antibodies, the OC antibody recognizes a generic epitope of the protein backbone present in fibrillar conformations, independent of protein sequence. ${ }^{27}$ Because of this, it is difficult to conclude about a specific location of interaction between BBG and $A \beta$ fibrils that would facilitate the decrease in OC signal due to binding without additional studies. However, structural models of A $\beta 40$ protofibrils have proposed that the hydrophobic $\mathrm{C}$-terminus of the $\mathrm{A} \beta$ peptide comprises the core of the cross-stacked $\beta$-sheet axis/backbone. ${ }^{38,136}$ Therefore, it is possible that the hydrophobic interactions between the six aromatic rings in each BBG molecule contribute to interaction with the hydrophobic Cterminus, thus destabilizing the fibrils. 
A

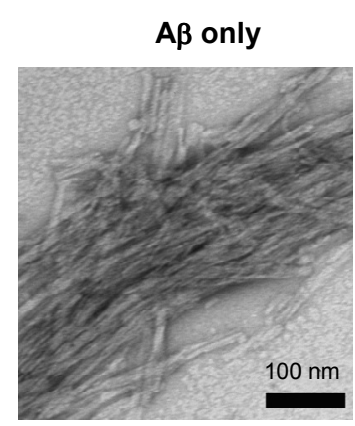

A $\beta$ only_M

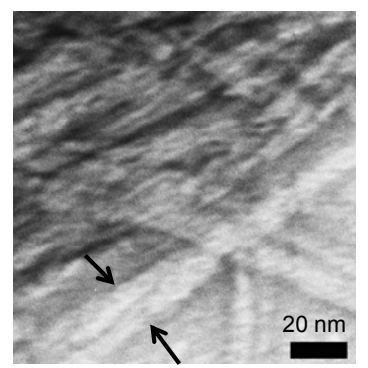

C

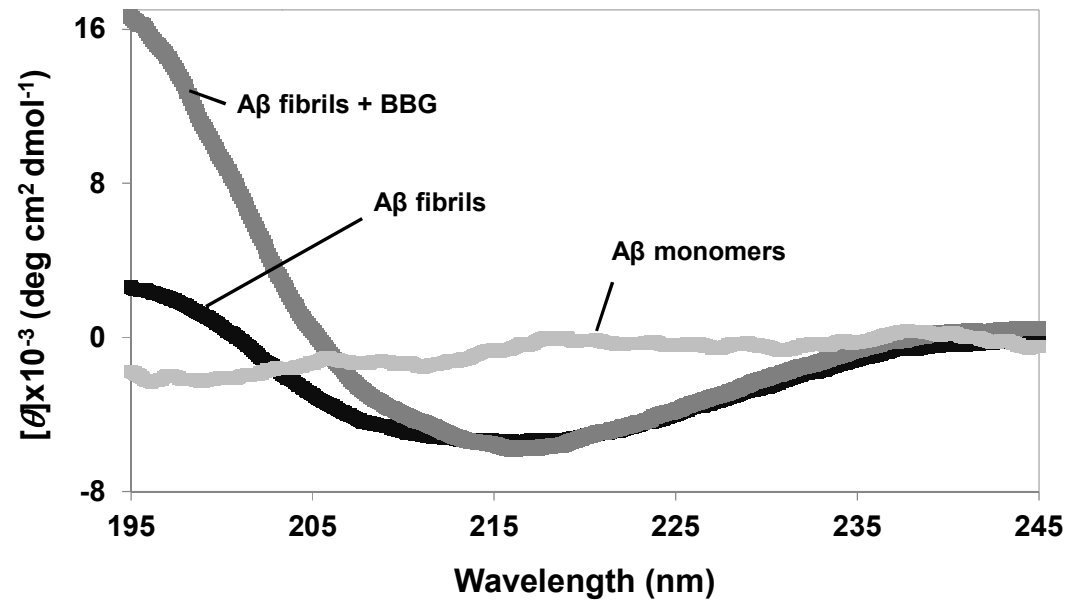

Figure 4. Properties of the $A \beta$ fibrils incubated in the absence or presence of BBG. TEM (A) and AFM images $(B, 1 \times 1 \mu \mathrm{m})$ of the $A \beta$ fibrils incubated for one day in the absence of any dye (Panel A $\beta$ only) or presence of 10x BBG (Panel BBG). The sections of the two TEM images were magnified (Panels $A \beta$ only_M and BBG_M). Each pair of arrows illustrates the width of the $A \beta$ aggregates. TEM scale bar is $100 \mathrm{~nm}$ (Top Panels) or 20 nm (Bottom Panels). (C) $C D$ spectra of $A \beta$ monomers, $A \beta$ fibrils incubated in the absence (A $\beta$ fibrils) or presence of 10x BBG (A $\beta$ fibrils $+\mathrm{BBG}$ ) for one day. 
Table 1: Measured $^{\mathrm{a}}$ TEM length (A) and width (B) distribution ${ }^{\mathrm{b}}$ of $\mathrm{A} \beta$ fibrils incubated in the presence or absence of $10 \mathrm{X}$ BBG and 10X ER for one day at $37^{\circ} \mathrm{C}$.

A.

\begin{tabular}{|c|c|c|c|c|c|c|c|c|c|c|c|c|c|}
\hline & \multicolumn{7}{|c|}{ Length of A $\beta$ Aggregates $(\mu \mathrm{m})$} & & \\
\hline & 0.1 & 0.2 & 0.3 & 0.4 & 0.5 & 0.6 & 0.7 & 0.8 & 0.9 & 1 & 1.1 & $>1.1$ & $\begin{array}{c}\text { Average } \\
(\mathrm{nm})\end{array}$ \\
\hline Fibrils & $\mathrm{ND}$ & $2 \%$ & $4 \%$ & $8 \%$ & $10 \%$ & $10 \%$ & $6 \%$ & $10 \%$ & $4 \%$ & $2 \%$ & $10 \%$ & $35 \%$ & $1026 \pm 621$ \\
Only & & & & & & & & & & & & & \\
\hline $10 \mathrm{XBG}$ & $34 \%$ & $54 \%$ & $9 \%$ & $3 \%$ & $\mathrm{ND}$ & $\mathrm{ND}$ & $\mathrm{ND}$ & $\mathrm{ND}$ & $\mathrm{ND}$ & $\mathrm{ND}$ & $\mathrm{ND}$ & $\mathrm{ND}$ & $133 \pm 65$ \\
\hline $10 \mathrm{X}$ ER & $3 \%$ & $18 \%$ & $32 \%$ & $32 \%$ & $9 \%$ & $3 \%$ & $2 \%$ & $1 \%$ & $\mathrm{ND}$ & $\mathrm{ND}$ & $\mathrm{ND}$ & $\mathrm{ND}$ & $303 \pm 129$ \\
\hline
\end{tabular}

B.

\begin{tabular}{|c|c|c|c|c|c|c|c|c|c|c|c|c|c|c|}
\hline & \multicolumn{10}{|c|}{ Width of A $\beta$ Aggregates (nm) } & & \\
\hline & 6 & 8 & 10 & 12 & 14 & 16 & 18 & 20 & 22 & 24 & 26 & 28 & $>28$ & $\begin{array}{c}\text { Average } \\
(\mathrm{nm})\end{array}$ \\
\hline $\begin{array}{c}\text { Fibrils } \\
\text { Only }\end{array}$ & $\mathrm{ND}$ & $\mathrm{ND}$ & $\mathrm{ND}$ & $2 \%$ & $10 \%$ & $10 \%$ & $25 \%$ & $13 \%$ & $21 \%$ & $10 \%$ & $4 \%$ & $4 \%$ & $1 \%$ & $19 \pm 4$ \\
\hline $10 \mathrm{X}$ BBG & $\mathrm{ND}$ & $\mathrm{ND}$ & $\mathrm{ND}$ & $\mathrm{ND}$ & $\mathrm{ND}$ & $1 \%$ & $10 \%$ & $4 \%$ & $10 \%$ & $11 \%$ & $19 \%$ & $8 \%$ & $37 \%$ & $26 \pm 7$ \\
\hline $10 \mathrm{X}$ ER & $1 \%$ & $7 \%$ & $48 \%$ & $25 \%$ & $17 \%$ & $2 \%$ & $\mathrm{ND}$ & $\mathrm{ND}$ & $\mathrm{ND}$ & $\mathrm{ND}$ & $\mathrm{ND}$ & $\mathrm{ND}$ & $\mathrm{ND}$ & $10 \pm 2$ \\
\hline
\end{tabular}

${ }^{a}$ Measured using Image $\mathrm{J}$ software.

${ }^{\mathrm{b}}$ The aggregate length or width bin labels represent the maximum length or width of aggregates in each respective bin. Shown on the table are the proportions of each sample population measured possessing the respective maximum bin length or width. Minimum one hundred aggregates except fifty one fibrils only aggregates for length distribution were used to obtain the distribution.

ND: Not Detected 
Table 2: Secondary structure content ${ }^{\mathrm{a}}$ of $\mathrm{A} \beta$ fibrils incubated ${ }^{\mathrm{b}}$ in the absence or presence of $\mathrm{BBG}$ or ER.

\begin{tabular}{|c|c|c|c|c|}
\hline Dye added $^{\mathrm{c}}$ & $\alpha$-helix & $\beta$-sheet & $\beta$-turn & Disordered \\
\hline- & $12.2 \%$ & $36.4 \%$ & $12.1 \%$ & $39.3 \%$ \\
\hline BBG & $12.8 \%$ & $44.4 \%$ & $9.9 \%$ & $32.9 \%$ \\
\hline ER & $12.7 \%$ & $36.8 \%$ & $11.8 \%$ & $38.6 \%$ \\
\hline
\end{tabular}

${ }^{a}$ Determined by DichroWeb using CONTIN method and SP175 reference proteins

${ }^{\mathrm{b}}$ Incubated at $37{ }^{\circ} \mathrm{C}$ without shaking for one day.

${ }^{\mathrm{c}} \mathrm{A} \beta$ :small molecule $(\mathrm{BBG}$ or $\mathrm{ER})=1: 10$ molar ratio 


\section{Incubation Time}

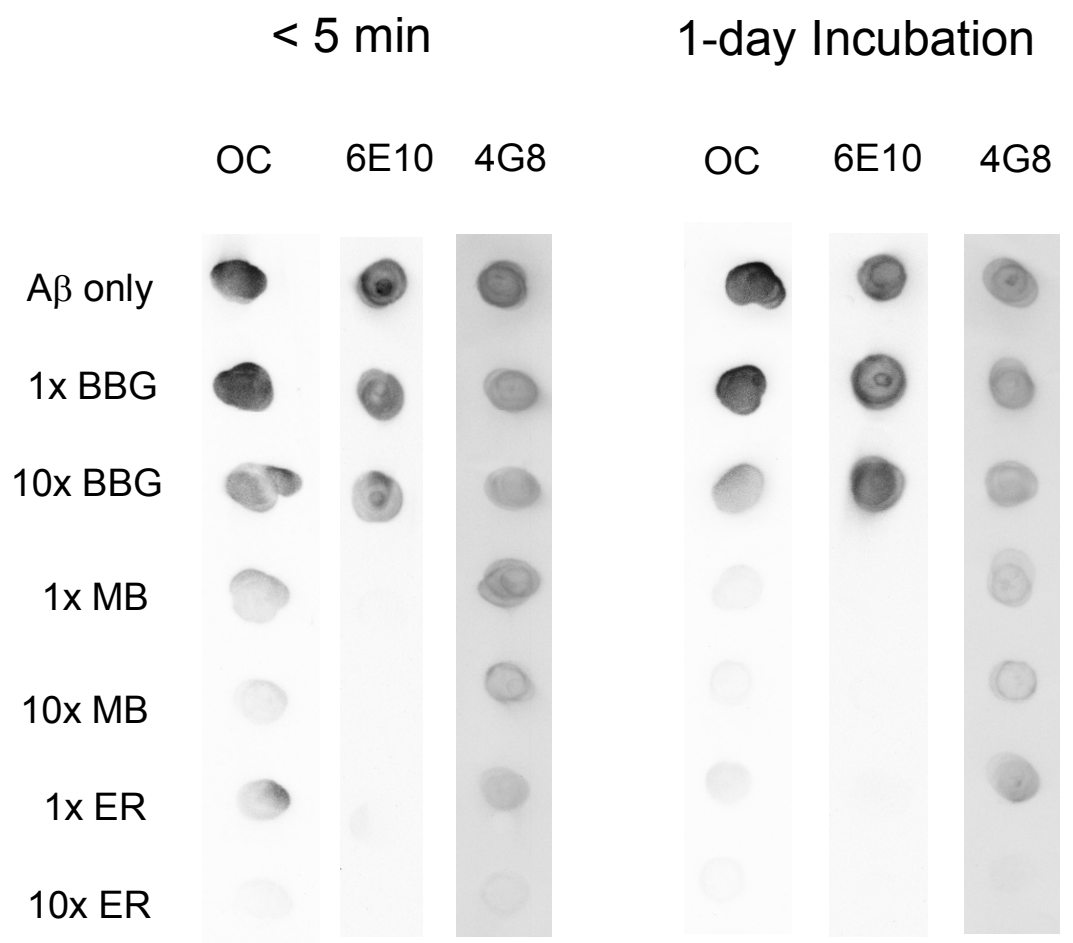

Figure 5. Dot-blot images of the $A \beta$ fibrils incubated in the absence ( $A \beta$ only) or presence of $1 \mathrm{x}$ and $10 \mathrm{x} \mathrm{BBG}, \mathrm{MB}$, or ER for less than 5 minutes (Panel $<5 \mathrm{~min}$ ) or one day (Panel 1-day incubation). For each antibody, all samples were spotted onto the same nitrocellulose membrane. Each membrane was immuno-stained with the OC, 6E10, or 4G8 antibody. For clearer presentation of the data, the sections of each membrane were cut and re-arranged. 


\subsection{MB Converts Preformed A $\beta$ fibrils into Amorphous Aggregates.}

Next, $A \beta$ fibrils were treated with 1x or 10x MB for one day. The TEM and AFM images of the MB-treated A $\beta$ fibrils showed that no structural features of fibrils were observed (lacking a persistent defined structure), and neither the size nor the shape of the MB-treated A $\beta$ aggregates were homogenous (Figure 6A), indicating the possibility of structural changes from fibrils to amorphous aggregates. The $\mathrm{CD}$ spectrum of the MB-treated $A \beta$ fibrils showed three changes from that of $A \beta$ fibrils - a shift in the wavelength of a minimum ellipticity, negative ellipticity below $200 \mathrm{~nm}$, and an upward shift of ellipticity above $200 \mathrm{~nm}$ toward zero (Figure 6B). Furthermore, the CD spectrum of the MB-treated A $\beta$ fibrils shifted toward that of the $A \beta$ monomers (Figure 6B). Because $A \beta$ monomers have been shown to possess predominantly disordered/random-coil secondary structure ${ }^{6,31}$ and low ellipticity above $210 \mathrm{~nm}$ and negative banding at $195 \mathrm{~nm}$ are general characteristics of disordered proteins, ${ }^{99}$ the changes observed with MB-treated fibrils strongly indicate a substantial loss of the $\beta$-sheet content but an increase in the disordered structural content. Similar to the BBG-treated A $\beta$ fibrils, the CD spectrum of the MB-treated $A \beta$ fibrils was used to estimate the secondary structure content numerically using DichroWeb. Because the SP175 reference set contains the greatest range of protein structures/conformations among the total eight reference sets explicitly described in DichroWeb, our first choice was to employ this reference set for the $\mathrm{CD}$ analysis with all three small molecules (BBG, $\mathrm{MB}$, and ER). However, when we used the SP175 reference protein set to analyze the MB-treated fibril CD spectrum, no significant change in the secondary structure content was observed despite the obvious changes in the spectrum described previously (Table S2 in the Supporting Information). After searching through the literature for a possible explanation to this disparity, we found that the accuracy of the secondary structure content deconvolution estimation greatly relies on the choice of a reference protein set containing proteins with similar structure to the one being studied. ${ }^{91,123}$ Since many of the intrinsically disordered amyloidogenic proteins do not fold into only one stable conformation that can be used to construct a reference set, finding an appropriate reference set for intrinsically disordered $A \beta$ is 
particularly challenging. To our knowledge, there are no existing reference sets containing intrinsically disordered monomeric peptides/proteins, such as A $\beta$ monomer. After thoroughly examining the SP175 reference protein set, ${ }^{124}$ we found that $\alpha$-helix-, $\beta$-sheet, and $\beta$-turn -rich reference proteins are well represented in the SP175 reference set, allowing successful estimation of the secondary structure contents of numerous folded proteins. However, we also found that the SP175 set includes only 1-2 disordered reference proteins among a total of 72 reference proteins. Since the proteins used to construct the SP175 reference set were prepared by folding recombinant proteins produced from bacteria, denatured or unfolded proteins were rarely included. Such a relatively low frequency of the disordered reference proteins is most likely attributed to the underestimated disordered structure content. In fact, the developers of the SP175 reference set also acknowledged that the validity of the reference set is limited to $\alpha$-helical and $\beta$-rich proteins, not disordered proteins. ${ }^{124}$ This further underlines the importance of performing an in-depth review of the reference set being used before beginning the analysis.

In order to address the issue of finding an appropriate reference set for the spectrum of the MBtreated $A \beta$ fibrils, different reference protein sets contained within the DichroWeb server were evaluated. Among the reference protein sets embedded in DichroWeb, Set No. 6 has the highest frequency of disordered reference proteins (11 out of 42 total reference proteins). Therefore, the secondary structure contents of both the $A \beta$ fibrils and the MB-treated $A \beta$ fibrils were re-evaluated using the Set No. 6 and the estimated values are presented in Table 3. Compared to the A $\beta$ fibrils, the MB-treated $A \beta$ fibrils exhibited a significant reduction in the $\beta$-sheet and $\beta$-turn content, but a substantial increase in the unordered structure content, which is quite consistent with the observation of the amorphous aggregates in the TEM monograph, AFM scan (Figure 6A), and qualitative visual analysis of the CD spectra. To our knowledge, conversion of $\mathrm{A} \boldsymbol{\beta}$ fibrils into disordered-structured aggregates has not been shown previously through numerical deconvolution analysis of corresponding CD spectra. 
The interaction between $\mathrm{MB}$ and preformed $\mathrm{A} \beta 40$ fibrils was further explored using dot-blotting with $6 \mathrm{E} 10$, OC, and 4G8 antibodies. Incubation of $\mathrm{A} \beta$ fibrils with either 1x or 10x MB for a very short time (less than $5 \mathrm{~min}$ ) led to a substantial loss of the OC-reactivity (Figure 5; Panel $<5$ min), clearly indicating that $\mathrm{MB}$ binds to the $\mathrm{OC}$ antibody epitope. Because of this strong binding affinity of MB to the OC antibody epitope, it is difficult to discern whether the weak OC signals observed in the MBtreated fibrils for 1 day (Figure 5, Panel 1 day) can be attributed to the direct MB binding to the OC epitope or the structural changes induced by MB (resulting in loss of the cross-stacked $\beta$-sheet epitope). The $\mathrm{A} \beta$ fibrils treated with $\mathrm{MB}$ for a short time also led to a complete loss of the $6 \mathrm{E} 10$ reactivity, indicating that $\mathrm{MB}$ binds to the $6 \mathrm{E} 10$ antibody epitope (residues $1-16$ of $\mathrm{A} \beta$ ). According to the structural model of $A \beta$ fibrils, the $N$-terminus of $A \beta$ (residues $1-16$ ) is involved in the assembly of two protofibrils into one fibril. ${ }^{38}$ Therefore, we speculate that MB destabilizes fibrils into amorphous aggregates at least in part via MB binding to a joint region between the two protofibrillar components of an $\mathrm{A} \beta$ fibril. ${ }^{1} \mathrm{MB}$ carries a positive charge at neutral $\mathrm{pH}$, and therefore, has the potential to interact with negatively charged amino acids in the N-terminus of $\mathrm{A} \beta$ (Aspartic and/or Glutamic Acid) through electrostatic interactions.

Table 3: Secondary structure content ${ }^{\mathrm{a}}$ of $\mathrm{A} \beta$ fibrils incubated $^{\mathrm{b}}$ in the absence or presence of MB.

\begin{tabular}{|c|c|c|c|c|}
\hline Small molecule added $^{\mathrm{c}}$ & $\alpha$-helix & $\beta$-sheet & $\beta$-turn & Disordered \\
\hline- & $10.1 \%$ & $32.2 \%$ & $27.4 \%$ & $30.3 \%$ \\
\hline MB & $8.4 \%$ & $18.3 \%$ & $4.3 \%$ & $69.0 \%$ \\
\hline
\end{tabular}

${ }^{\text {a }}$ Determined by DichroWeb using CONTIN method and Set 6 reference proteins

${ }^{\mathrm{b}}$ Incubated at $37^{\circ} \mathrm{C}$ without shaking for one day.

${ }^{\mathrm{c}} \mathrm{A} \beta: \mathrm{MB}=1: 10$ molar ratio 


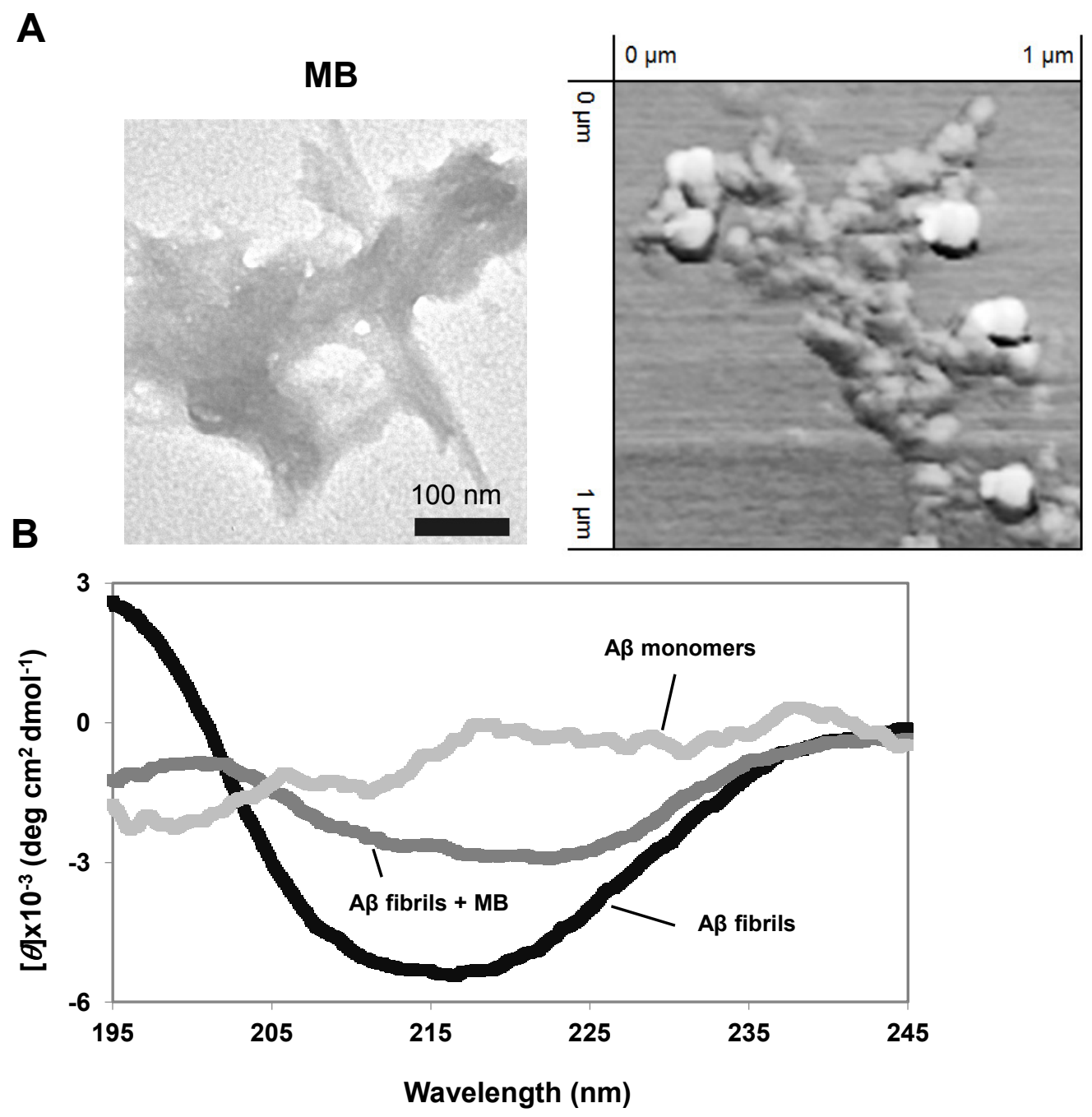

Figure 6. Properties of the $A \beta$ fibrils incubated in the absence or presence of MB. (A) TEM (left panel) and AFM (right panel, 1x1 $\mu \mathrm{m}$ ) images of the A $\beta$ fibrils incubated for one day in the presence of 10x MB. TEM scale bar is $100 \mathrm{~nm}$. (B) CD spectra of A $\beta$ monomers, $A \beta$ fibrils incubated in the absence (A $\beta$ fibrils) or presence of $10 x \mathrm{MB}(\mathrm{A} \beta$ fibrils $+\mathrm{MB}$ ) for one day. 


\subsection{ER Disrupts Preformed A $\beta$ fibrils into Protofibrils.}

In order to investigate the action of the third small molecule modulator, $1 \mathrm{x}$ or $10 \mathrm{x}$ ER was incubated with the $A \beta$ fibrils for one day. The TEM image of the ER-treated A $\beta$ fibrils showed many filamentous, persistent fibrillar structures (Figure 7A and Figure S2; ER panel for wider frame in Supporting Information - Section 9) that seemed to be less tightly bundled/stacked than the untreated fibril sample (Figure 4A-B; A $\beta$ only panels and Figure S2; A $\beta$ only panel in Supporting Information Section 9). The average length of the ER-treated fibrils measured using TEM was $303 \pm 129 \mathrm{~nm}$, less than the average length of the untreated fibrils mentioned previously, but longer than the fibrils treated with 10X BBG (Table 1A). The majority (73\%) of the ER-treated aggregates measured had a length between 200 and $500 \mathrm{~nm}$. Next, the morphological fate trends of A $\beta$ fibrils remodeled with ER were investigated using AFM and compared to the TEM findings. Similar to TEM, the AFM scan of the ERtreated $A \beta$ fibrils (Figure 7B) showed many fibrillar structures, still in close proximity to each other, but less stacked than with the untreated fibril sample (Figure 4B; A $\beta$ only panel). From the AFM scan, the average length of the ER-treated sample was found to be $162 \pm 60 \mathrm{~nm}$ (Table S1 in the Supporting Information - Section 9). This length data matched the trend seen in the TEM data that the ER-treated fibrils were shorter than the untreated A $\beta$ fibrils, but longer than the BBG-treated sample's aggregate population. As was the case for the untreated- and the BBG-treated $A \beta$ samples, the average length of the ER-treated sample measured by AFM is shorter than that by TEM, likely because AFM detects shorter A $\beta$ aggregates better than TEM. The ER-treated A $\beta$ aggregates (with persistent filamentous structure) that are shorter than the untreated $A \beta$ fibrils could be protofibrils or $A \beta$ fibril fragments.

In order to determine whether the ER-treated aggregates are protofibrils or fibril fragments, their widths were measured and compared to those of untreated A $\beta$ fibrils. From the TEM images (Figure 7A: ER_M Panel and Figure S2 in the Supporting Information), the average width of the ER-induced aggregates is significantly smaller than that of both the untreated A $\beta$ fibrils and the $10 \mathrm{X}$ BBG-treated $\mathrm{A} \beta$ fibrils (Table 1B). The average measured width of the ER-treated A $\beta$ fibrils was $10 \pm 2 \mathrm{~nm}$, which 
matches well with the width of an individual protofibril according to the A $\beta$ protofibrils and fibrils structural model discussed previously. ${ }^{38}$ Furthermore, none of the ER-treated A $\beta$ fibrils measured displayed widths greater than $16 \mathrm{~nm}$, whereas $78 \%$ and $99 \%$, respectively, of the untreated $\mathrm{A} \beta$ fibrils and the BBG-treated fibrils samples measured contained widths greater than the $16 \mathrm{~nm}$ cutoff. It is also noteworthy to mention that co-incubation of $A \beta$ monomer with ER also led to formation of dominant protofibrils with the width of $12 \mathrm{~nm} .{ }^{39}$ Furthermore, the ER-treated samples did not exhibit the twisted structure, a typical feature of $A \beta$ fibrils in general and also observed in our untreated $A \beta$ fibril samples, in the TEM images (Figure 7A for ER-treated sample and Figure 4A for A $\beta$ only sample). Moreover, the widths of the ER-treated aggregates $(35 \pm 6 \mathrm{~nm})$ analyzed using AFM were much thinner than the $\mathrm{A} \beta$ fibril $(73 \pm 23 \mathrm{~nm})$ and BBG-treated samples $(58 \pm 14 \mathrm{~nm})$ (Table $\mathrm{S} 1 \mathrm{~B}$ in the Supporting Information - Section 9), reinforcing the trend found in the TEM analysis. In fact, the width distribution data show that only $6 \%$ of the ER-treated sample's aggregate population displayed widths within one standard deviation from the $73 \mathrm{~nm}$ mean width for the untreated fibril sample. Because of these morphological changes/findings, the ER-treated A $\beta$ fibrils are most likely protofibrils. As was the case for the untreated $A \beta$ fibrils and the BBG-treated $A \beta$ fibrils, the width of the ER-treated $A \beta$ fibrils determined by AFM is considered over-estimated compared to the width determined of TEM due to the lateral convolution caused by cantilever tip radius. ${ }^{89,125}$

The CD spectrum of the ER-treated A $\beta$ fibrils clearly shows typical features of $\beta$-sheet-rich structure (Figure 7C). The estimates of the secondary structure content of the ER-treated A $\beta$ fibrils are essentially the same as those of $A \beta$ fibrils (Table 2), indicating that the ER-treated $A \beta$ fibrils are $\beta$-sheet -rich, and most likely fibrillar structures.

In the dot-blot assays, the short time incubation (less than 5 minutes) of the $A \beta$ fibrils with $1 \mathrm{x}$ or 10x ER led to a significant reduction of the OC-reactivity (Figure 5), clearly indicating that ER binds to the OC antibody epitope (as was the case with MB). Further, both 1x and 10x ER led to a complete loss of the $6 \mathrm{E} 10$ reactivity indicating that a primary ER binding site on $\mathrm{A} \beta$ is located at the $6 \mathrm{E} 10$ antibody epitope (A $\beta$ N-terminus), which is consistent with the results reported previously. ${ }^{39}$ As mentioned 
previously in the structural model of $A \beta$ fibrils, the N-terminus of $A \beta$ (residues $1-16$ ) is involved in the assembly of two protofibrils into one fibril. Therefore, we conclude that ER separates fibrils in to the ER-induced protofibrils by binding to the N-terminus of the two protofibrillar components of $A \beta$ fibrils, thus destabilizing the fibril complex. ${ }^{1}$ Although both MB and ER were shown to bind to the N-terminus of $A \beta$ sequence, they most likely interact with different residues in $A \beta . M B$ has a positive charge, but ER has negative charges at neutral $\mathrm{pH}$. Therefore, we speculate that ER interacts with positively charged residues in the N-terminus of $A \beta$ (one Lysine, one Arginine, and/or the three Histidines present in the N-terminus of $A \beta$ ), which led to a different fate of the destabilized $A \beta$ fibrils compared to the action of MB. 
ER

A

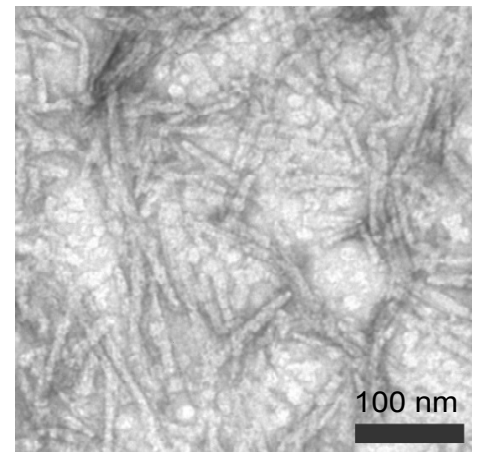

ER_M

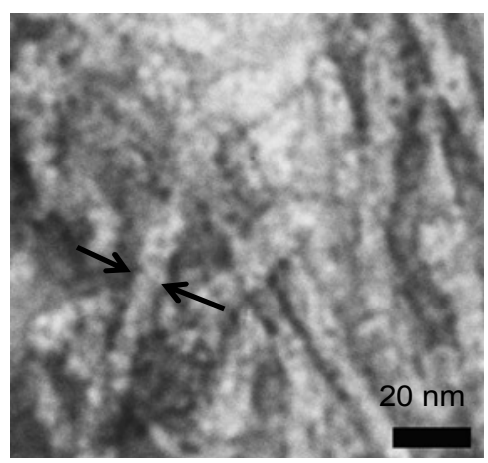

B

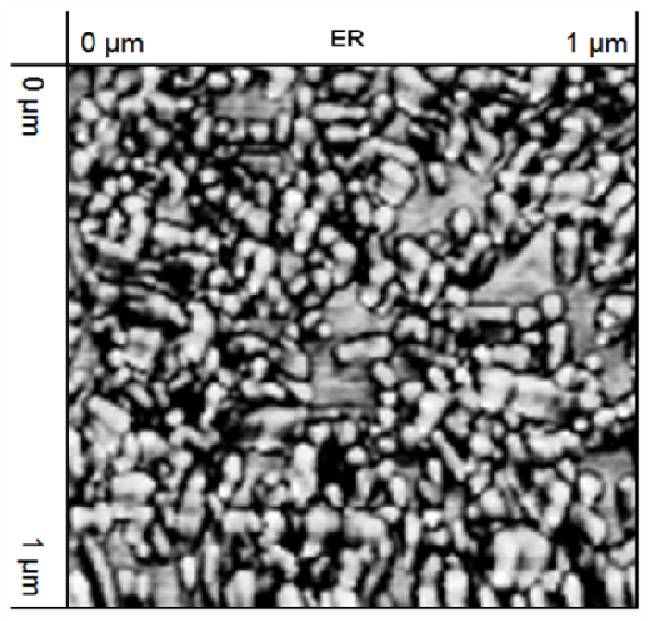

\section{C}

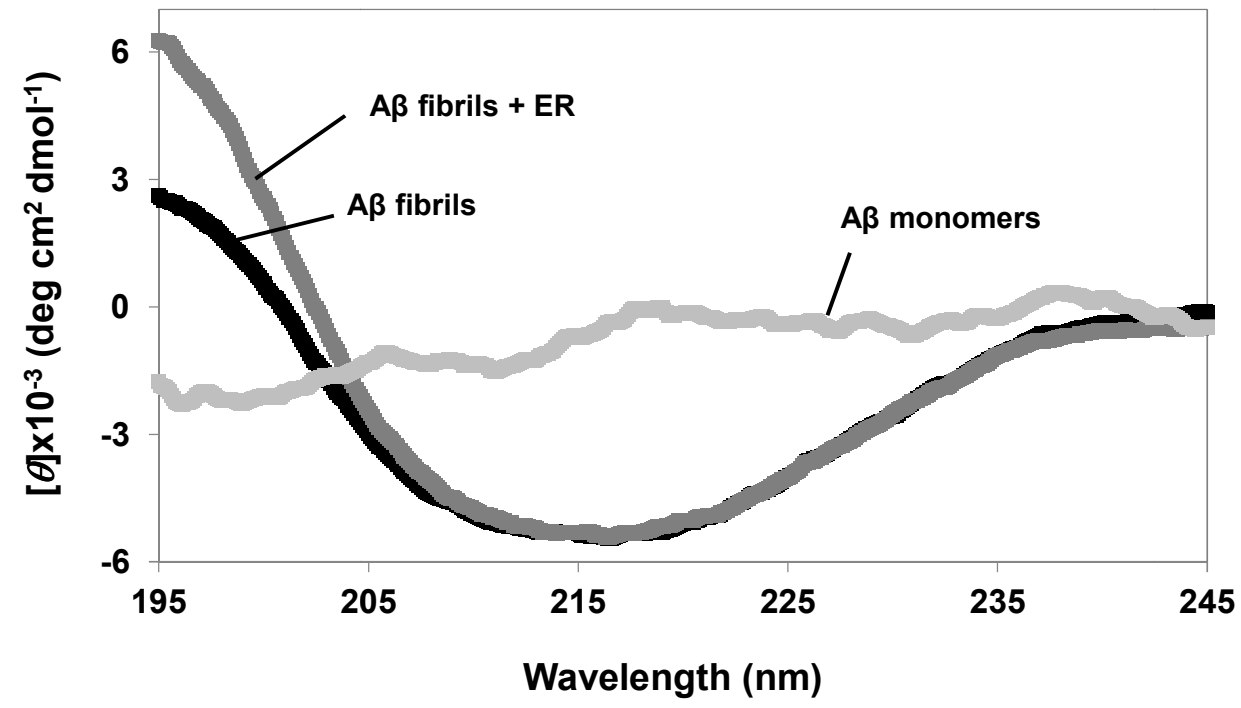

Figure 7. Properties of the $A \beta$ fibrils incubated in the absence or presence of ER. TEM (A) and $\operatorname{AFM}(B, 1 \times 1 \mu \mathrm{m})$ images of the $\mathrm{A} \beta$ fibrils incubated for one day in the presence of 10x ER (Panel ER) and the magnified section (Panel ER_M). The pair of arrows illustrate the width of the $A \beta$ aggregates. TEM scale bar is $100 \mathrm{~nm}$ (Panel ER) or $20 \mathrm{~nm}$ (Panel ER_M). (C) CD spectra of $A \beta$ monomers, $A \beta$ fibrils incubated in the absence (A $\beta$ fibrils) or presence of $10 x$ ER (A $\beta$ fibrils $+E R)$ for one day. 


\section{Conclusions}

In this thesis work, we evaluated three biocompatible small molecule $A \beta$ aggregation modulators (BBG, MB, and ER) for their capacities to trigger structural changes of the $A \beta$ fibrils in a physiologically-relevant manner and then characterized the structural features of the restructured $A \beta$ fibrils and the mechanisms by which the changes occur.

All research objectives were met:

1. Morphology of the remodeled A $\beta$ aggregates was assessed using TEM and AFM.

2. Secondary structure of remodeled aggregates was assessed using CD spectra analysis.

3. Remodeled $A \beta$ aggregates were classified using the criteria for various conformers discussed in Section 1.2.

Combined with TEM, AFM, and dot-blot assays, conversion of A $\beta$ fibrils into different types of aggregates was quantitatively analyzed through numerical deconvolution analysis of corresponding $\mathrm{CD}$ spectra with appropriate choices of reference protein sets. Incubation of the preformed A $\beta$ fibrils with these molecules (BBG, MB, and ER) effectively destabilized the preformed $A \beta$ fibrils but led to three distinct fates. $\mathrm{BBG}$ fragmented the $\mathrm{A} \beta$ fibrils into shorter fibrils. $\mathrm{MB}$ restructured the $\mathrm{A} \beta$ fibrils into amorphous aggregates. Finally, ER separated the A $\beta$ fibrils into protofibrils.

4. Morphological changes and/or binding sites of the three small molecules were assessed using conformational and sequence-specific antibody dot blot analysis. 
We found that BBG binds to the OC antibody epitope. Previously, it was shown that BBG binds to $A \beta$ peptide in multiple sites. ${ }^{100}$ Therefore, it is likely that direct binding of $B B G$ to $A \beta$ fibrils causes the $A \beta$ fibril fragmentation. We also found that both $M B$ and ER bind to the N-terminus of $A \beta$, a joining region between two protofibrils in the formation of one $\mathrm{A} \beta$ fibril. Therefore, we speculate that $\mathrm{MB}$ or ER binding to the joint between two protofibrils is a key step that triggers drastic structural changes of the $A \beta$ fibrils into amorphous aggregates or separate protofibrils, respectively. 


\section{$\underline{\text { 7. Recommendations }}$}

This investigation has conclusively established that thermodynamically stable preformed $A \beta$ fibrils can be destabilized or remodeled by three small molecules (BBG, MB, and ER). Because of this, these three biocompatible molecules are promising candidates to remove insoluble amyloid fibrils deposited in the human brain associated with Alzheimer's disease. Therefore, as a next step, they would be well suited for study in animals to confirm efficacy in a living model. The results also successfully illustrate the possibility of controlling changes in biomolecule-based nanostructures using chemical compounds.

In addition to the experiments performed, there are several logical continuations of studying the effect of these three small molecules on preformed $A \beta 40$ fibrils in vitro that could provide fascinating insights. First, an investigation of the binding/dissociation constant of the small molecules to $A \beta$ fibrils would yield interesting information on both the binding affinity and number of binding sites for each molecule. Second, monomer seeding experiments could be performed to determine if the remodeled A $\beta$ fibrils can be considered "on" or "off-pathway" ("on-pathway" if the restructured aggregates can seed/accelerate fibril formation from the monomer state). Third, it would be interesting to test whether or not the restructured aggregates are non-covalently associated by exposing them to high temperatures and observe if dissociation occurs. Fourth, in this thesis work, high concentrations of small molecules (10X molar excess over $A \beta$ ) and a one-day restructuring period were used in order to observe overall/ending structure change. However, it would provide interesting insight to perform a similar set of analyses using lower concentrations of small molecules and/or shorter restructuring time to characterize the progression of the change. Lastly, it would be interesting to remove the small molecules from the restructured aggregates by desalting and determine if the structural changes are reversible or not. 


\section{Literature Cited}

1. Irwin, J. A.; Wong, H. E.; Kwon, I., Different Fates of Alzheimer's Disease Amyloid-beta

Fibrils Remodeled by Biocompatible Small Molecules. Biomacromolecules 2012, http://dx.doi.org/10.1021/bm3016994.

2. Hardy, J.; Higgins, G., Alzheimer's Disease: The Amyloid Cascade Hypothesis. Science 1992, $256,184-185$.

3. Li, J.; Uversky, V. N.; Fink, A. L., Effect of familial Parkinson's disease point mutations A30P and A53T on the structural properties, aggregation, and fibrillation of human alpha-synuclein. Biochemistry 2001, 40, (38), 11604-11613.

4. Li, J.; Zhu, M.; Rajamani, S.; Uversky, V. N.; Fink, A. L., Rifampicin Inhibits $\alpha$-Synuclein Fibrillation and Disaggregates Fibrils. Chem. Biol. (Cambridge, MA, U. S.) 2004, 11, (11), 1513-1521.

5. Spillantini, M. G.; Crowther, R. A.; Jakes, R.; Cairns, N. J.; Lantos, P. L.; Goedert, M., Filamentous alpha-synuclein inclusions link multiple system atrophy with Parkinson's disease and dementia with Lewy bodies. Neurosci. Lett. 1998, 251, (3), 205-208.

6. Gregoire, S.; Irwin, J.; Kwon, I., Techniques for monitoring protein misfolding and aggregation in vitro and in living cells. Korean J. Chem. Eng. 2012, 29, (6), 693-702.

7. Jahn, T. R.; Radford, S. E., The Yin and Yang of protein folding. FEBS J. 2005, 272, (23), 59625970.

8. Jones, O. G.; Mezzenga, R., Inhibiting, promoting, and preserving stability of functional protein fibrils. Soft Matter 2012, 8, (4), 876-895.

9. Chatani, E.; Lee, Y.-H.; Yagi, H.; Yoshimura, Y.; Naiki, H.; Goto, Y., Ultrasonicationdependent production and breakdown lead to minimum-sized amyloid fibrils. Proc. Natl. Acad. Sci. U. S. A. 2009, 106, (27), 11119-11124. 
10. Arora, A.; Ha, C.; Park, C. B., Insulin amyloid fibrillation at above $100^{\circ} \mathrm{C}$ : New insights into protein folding under extreme temperatures. Protein Sci. 2004, 13, (9), 2429-2436.

11. Dubois, J.; Ismail; Chan; Ali, K., Fourier Transform Infrared Spectroscopic Investigation of Temperature- and Pressure-Induced Disaggregation of Amyloid A. Scand. J. Immunol. 1999, 49, (4), 376-380.

12. Adamcik, J.; Mezzenga, R., Adjustable twisting periodic pitch of amyloid fibrils. Soft Matter 2011, 7, (11), 5437-5443.

13. Narimoto, T.; Sakurai, K.; Okamoto, A.; Chatani, E.; Hoshino, M.; Hasegawa, K.; Naiki, H.; Goto, Y., Conformational stability of amyloid fibrils of $\beta 2$-microglobulin probed by guanidinehydrochloride-induced unfolding. FEBS Lett. 2004, 576, (3), 313-319.

14. Hirota-Nakaoka, N.; Hasegawa, K.; Naiki, H.; Goto, Y., Dissolution of $\beta 2-M i c r o g l o b u l i n$ Amyloid Fibrils by Dimethylsulfoxide. J. Biochem. 2003, 134, (1), 159-164.

15. Jordens, S.; Adamcik, J.; Amar-Yuli, I.; Mezzenga, R., Disassembly and Reassembly of Amyloid Fibrils in Water-Ethanol Mixtures. Biomacromolecules 2010, 12, (1), 187-193.

16. Li, J.; Zhu, M.; Manning-Bog, A. B.; Di Monte, D. A.; Fink, A. L., Dopamine and L-dopa disaggregate amyloid fibrils: implications for Parkinson's and Alzheimer's disease. FASEB J. 2004, 18, (9), 962-964.

17. Benilova, I.; Karran, E.; De Strooper, B., The toxic A[beta] oligomer and Alzheimer's disease: an emperor in need of clothes. Nat. Neurosci. 2012, 15, (3), 349-357.

18. Ruhs, P. A.; Adamcik, J.; Bolisetty, S.; Sanchez-Ferrer, A.; Mezzenga, R., A supramolecular bottle-brush approach to disassemble amyloid fibrils. Soft Matter 2011, 7, (7), 3571-3579. 
19. Park, J.-W.; Lee, I.-H.; Hahn, J.-S.; Kim, J.; Chung, K. C.; Paik, S. R., Disintegration of amyloid fibrils of $\alpha$-synuclein by dequalinium. Biochim. Biophys. Acta, Gen. Subj. 2008, 1780, (10), 1156-1161.

20. Giorgetti, S.; Raimondi, S.; Pagano, K.; Relini, A.; Bucciantini, M.; Corazza, A.; Fogolari, F.; Codutti, L.; Salmona, M.; Mangione, P.; Colombo, L.; De Luigi, A.; Porcari, R.; Gliozzi, A.; Stefani, M.; Esposito, G.; Bellotti, V.; Stoppini, M., Effect of Tetracyclines on the Dynamics of Formation and Destructuration of $\beta 2-M i c r o g l o b u l i n$ Amyloid Fibrils. J. Biol. Chem. 2011, 286, (3), 2121-2131.

21. Bieschke, J.; Russ, J.; Friedrich, R. P.; Ehrnhoefer, D. E.; Wobst, H.; Neugebauer, K.; Wanker, E. E., EGCG remodels mature alpha-synuclein and amyloid-beta fibrils and reduces cellular toxicity. Proc. Natl. Acad. Sci. U. S. A. 2010, 107, (17), 7710-7715.

22. Bitan, G.; Kirkitadze, M. D.; Lomakin, A.; Vollers, S. S.; Benedek, G. B.; Teplow, D. B., Amyloid Beta-protein assembly: A $\beta 40$ and A $\beta 42$ oligomerize through distinct pathways. Proc. Natl. Acad. Sci. U. S. A. 2003, 100, (1), 330-335.

23. Ono, K.; Hasegawa, K.; Naiki, H.; Yamada, M., Anti-amyloidogenic activity of tannic acid and its activity to destabilize Alzheimer's beta-amyloid fibrils in vitro. Biochimica et biophysica acta 2004, 1690, (3), 193-202.

24. Glabe, C. C., Amyloid Accumulation and Pathogensis of Alzheimer ' s Disease : Significance of Monomeric, Oligomeric and Fibrillar Amyloid-Beta. Subcellular Biochemistry 2005, 38, 167-177.

25. Ladiwala, A. R. A.; Lin, J. C.; Bale, S. S.; Marcelino-Cruz, A. M.; Bhattacharya, M.; Dordick, J. S.; Tessier, P. M., Resveratrol selectively remodels soluble oligomers and fibrils of amyloid Abeta into off-pathway conformers. J. Biol. Chem. 2010, 285, (31), 24228-24237.

26. Ahmed, M.; Davis, J.; Aucoin, D.; Sato, T.; Ahuja, S.; Aimoto, S.; Elliott, J. I.; Van Nostrand, W. E.; Smith, S. O., Structural conversion of neurotoxic amyloid-beta(1-42) oligomers to fibrils. Nat. Struct. Mol. Biol. 2010, 17, (5), 561-567. 
27. Kayed, R.; Head, E.; Sarsoza, F.; Saing, T.; Cotman, C. W.; Necula, M.; Margol, L.; Wu, J.; Breydo, L.; Thompson, J. L.; Rasool, S.; Gurlo, T.; Butler, P.; Glabe, C. G., Fibril specific, conformation dependent antibodies recognize a generic epitope common to amyloid fibrils and fibrillar oligomers that is absent in prefibrillar oligomers. Mol. Neurodegener. 2007, 2, 18.

28. Ehrnhoefer, D. E.; Bieschke, J.; Boeddrich, A.; Herbst, M.; Masino, L.; Lurz, R.; Engemann, S.; Pastore, A.; Wanker, E. E., EGCG redirects amyloidogenic polypeptides into unstructured, off-pathway oligomers. Nat Struct Mol Biol 2008, 15, (6), 558-566.

29. Grelle, G.; Otto, A.; Lorenz, M.; Frank, R. F.; Wanker, E. E.; Bieschke, J., Black Tea Theaflavins Inhibit Formation of Toxic Amyloid- $\beta$ and $\alpha$-Synuclein Fibrils. Biochemistry 2011, 50, (49), 10624-10636.

30. Wood, S. J.; Maleeff, B.; Hart, T.; Wetzel, R., Physical, Morphological and Functional Differences between pH 5.8 and 7.4 Aggregates of the Alzheimer's Amyloid Peptide A $\beta$. Journal of Molecular Biology 1996, 256, (5), 870-877.

31. Bartolini, M.; Bertucci, C.; Bolognesi, M. L.; Cavalli, A.; Melchiorre, C.; Andrisano, V., Insight into the kinetic of amyloid beta (1-42) peptide self-aggregation: elucidation of inhibitors' mechanism of action. ChemBioChem 2007, 8, (17), 2152-61.

32. Wu, J. W.; Breydo, L.; Isas, J. M.; Lee, J.; Kuznetsov, Y. G.; Langen, R.; Glabe, C., Fibrillar oligomers nucleate the oligomerization of monomeric amyloid beta but do not seed fibril formation. $J$. Biol. Chem. 2010, 285, (9), 6071-9.

33. Kayed, R.; Pensalfini, A.; Margol, L.; Sokolov, Y.; Sarsoza, F.; Head, E.; Hall, J.; Glabe, C., Annular Protofibrils Are a Structurally and Functionally Distinct Type of Amyloid Oligomer. J. Biol. Chem. 2009, 284, (7), 4230-4237. 
34. Fändrich, M., Oligomeric Intermediates in Amyloid Formation: Structure Determination and Mechanisms of Toxicity. Journal of Molecular Biology 2012, 421, (4-5), 427-440.

35. Ladiwala, A. R. A.; Dordick, J. S.; Tessier, P. M., Aromatic Small Molecules Remodel Toxic Soluble Oligomers of Amyloid-beta through Three Independent Pathways. J. Biol. Chem. 2011, 286, (5), 3209-3218.

36. Reinke, A. a.; Gestwicki, J. E., Insight into amyloid structure using chemical probes. Chemical biology \& drug design 2011, 77, (6), 399-411.

37. Koo, E. H.; Lansbury, P. T.; Kelly, J. W., Amyloid diseases: Abnormal protein aggregation in neurodegeneration. Proceedings of the National Academy of Sciences 1999, 96, (18), 9989-9990.

38. Schmidt, M.; Sachse, C.; Richter, W.; Xu, C.; Fändrich, M.; Grigorieff, N., Comparison of Alzheimer $\mathrm{A} \beta(1-40)$ and $\mathrm{A} \beta(1-42)$ amyloid fibrils reveals similar protofilament structures. Proc. Natl. Acad. Sci. U. S. A. 2009, 106, (47), 19813-19818.

39. Wong, H. E.; Kwon, I., Xanthene Food Dye, as a Modulator of Alzheimer's Disease Amyloidbeta Peptide Aggregation and the Associated Impaired Neuronal Cell Function. PLoS ONE 2011, 6, (10), e25752.

40. Bhak, G.; Lee, J.-H.; Hahn, J.-S.; Paik, S. R., Granular Assembly of $\alpha$-Synuclein Leading to the Accelerated Amyloid Fibril Formation with Shear Stress. Plos One 2009, 4, (1), e4177.

41. Lee, J.-H.; Bhak, G.; Lee, S.-G.; Paik, S. R., Instantaneous Amyloid Fibril Formation of $\alpha-$ Synuclein from the Oligomeric Granular Structures in the Presence of Hexane. Biophysical Journal 2008, 95, (2), L16-L18.

42. Ryu, J.; Kanapathipillai, M.; Lentzen, G.; Park, C. B., Inhibition of $\beta$-amyloid peptide aggregation and neurotoxicity by $\alpha$-d-mannosylglycerate, a natural extremolyte. Peptides 2008, 29, (4), $578-584$. 
43. Fändrich, M.; Schmidt, M.; Grigorieff, N., Recent progress in understanding Alzheimer's $\beta$ amyloid structures. Trends in Biochemical Sciences 2011, 36, (6), 338-345.

44. Klement, K.; Wieligmann, K.; Meinhardt, J.; Hortschansky, P.; Richter, W.; Fändrich, M., Effect of Different Salt Ions on the Propensity of Aggregation and on the Structure of Alzheimer's A $\beta(1-40)$ Amyloid Fibrils. J. Mol. Biol. 2007, 373, (5), 1321-1333.

45. Bartolini, M.; Andrisano, V., Strategies for the Inhibition of Protein Aggregation in Human Diseases. ChemBioChem 2010, 11, (8), 1018-1035.

46. Colby, D. W.; Cassady, J. P.; Lin, G. C.; Ingram, V. M.; Wittrup, K. D., Stochastic kinetics of intracellular huntingtin aggregate formation. Nat. Chem. Biol. 2006, 2, (6), 319-323.

47. Keshet, B.; Gray, J. J.; Good, T. A., Structurally distinct toxicity inhibitors bind at common loci on beta-amyloid fibril. Protein Sci. 2010, 19, (12), 2291-2304.

48. Lee, S.; Fernandez, E. J.; Good, T. A., Role of aggregation conditions in structure, stability, and toxicity of intermediates in the A $\beta$ fibril formation pathway. Protein Science 2007, 16, (4), 723-732.

49. Murphy, R. M., Peptide aggregation in neurodegenerative disease. Annu. Rev. Biomed. Eng. 2002, 4, 155-174.

50. Pike, C. J.; Walencewicz, A. J.; Glabe, C. G.; Cotman, C. W., In vitro aging of beta-amyloid protein causes peptide aggregation and neurotoxicity. Brain Research 1991, 563, (1-2), 311-314.

51. Alzheimer's, A., 2010 Alzheimer's disease facts and figures. Alzheimer's \& dementia 2010, 6, (2), 158-194.

52. Kabuta, T.; Suzuki, Y.; Wada, K., Degradation of amyotrophic lateral sclerosis-linked mutant $\mathrm{Cu}, \mathrm{Zn}$-superoxide dismutase proteins by macroautophagy and the proteasome. J. Biol. Chem. 2006, 281, (41), 30524-30533. 
53. Niwa, J.; Yamada, S.; Ishigaki, S.; Sone, J.; Takahashi, M.; Katsuno, M.; Tanaka, F.; Doyu, M.;

Sobue, G., Disulfide bond mediates aggregation, toxicity, and ubiquitylation of familial amyotrophic lateral sclerosis-linked mutant SOD1. J. Biol. Chem. 2007, 282, (38), 28087-28095.

54. Kayed, R.; Head, E.; Thompson, J. L.; McIntire, T. M.; Milton, S. C.; Cotman, C. W.; Glabe, C. G., Common structure of soluble amyloid oligomers implies common mechanism of pathogenesis. Science 2003, 300, (5618), 486-9.

55. Glabe, C. G., Structural classification of toxic amyloid oligomers. The Journal of biological chemistry 2008, 283, (44), 29639-43.

56. Bucciantini, M.; Giannoni, E.; Chiti, F.; Baroni, F.; Formigli, L.; Zurdo, J.; Taddei, N.; Ramponi, G.; Dobson, C. M.; Stefani, M., Inherent toxicity of aggregates implies a common mechanism for protein misfolding diseases. Nature 2002, 416, (6880), 507-11.

57. Cleary, J. P.; Walsh, D. M.; Hofmeister, J. J.; Shankar, G. M.; Kuskowski, M. a.; Selkoe, D. J.; Ashe, K. H., Natural oligomers of the amyloid-beta protein specifically disrupt cognitive function. Nat. Neurosci. 2005, 8, (1), 79-84.

58. Reinke, A. a.; Gestwicki, J. E., Structure-activity relationships of amyloid beta-aggregation inhibitors based on curcumin: influence of linker length and flexibility. Chemical biology \& drug design 2007, 70, (3), 206-15.

59. Nilsson, M. R., Techniques to study amyloid fibril formation in vitro. Methods 2004, 34, 151160.

60. Groenning, M., Binding mode of Thioflavin $\mathrm{T}$ and other molecular probes in the context of amyloid fibrils_current status. Journal of Chemical Biology 2010, 3, (1), 1-18. 
61. Maezawa, I.; Hong, H.-S.; Liu, R.; Wu, C.-Y.; Cheng, R. H.; Kung, M.-P.; Kung, H. F.; Lam, K. S.; Oddo, S.; Laferla, F. M.; Jin, L.-W., Congo red and thioflavin-T analogs detect Abeta oligomers. J. Neurochem. 2008, 104, (2), 457-68.

62. Hudson, S. a.; Ecroyd, H.; Kee, T. W.; Carver, J. a., The thioflavin T fluorescence assay for amyloid fibril detection can be biased by the presence of exogenous compounds. FEBS J. 2009, 276, (20), 5960-72.

63. Biancalana, M.; Koide, S., Molecular Mechanism of Thioflavin-T binding to amyloid fibrils. Biochim. Biophys. Acta 2010, 1804, 1405-1412.

64. Hatters, D. M.; Griffin, M. D. W., Protein Folding, Misfolding, and Disease, ch. 8. Amyloid International Journal Of Experimental And Clinical Investigation 2011, 752, (4), 121-136.

65. Lindgren, M.; Hammarström, P., Amyloid oligomers: spectroscopic characterization of amyloidogenic protein states. The FEBS journal 2010, 277, (6), 1380-8.

66. Klunk, W. E.; Jacob, R. F.; Mason, R. P., Quantifying Amyloid by Congo Red Spectra Shift Assay. Methods Enzymol. 1999, 309, (1974), 6879-6879.

67. Walsh, D. M.; Hartley, D. M.; Kusumoto, Y.; Fezoui, Y.; Condron, M. M.; Lomakin, A.; Benedek, G. B.; Selkoe, D. J.; Teplow, D. B.; Biol, D. B. J., Amyloid Beta Protein Fibrillogenesis. J. Biol. Chem. 1999, 274, (36), 25945-25952.

68. LeVine, H., III; Walker, L. C., Molecular polymorphism of amyloid-beta in Alzheimer's disease. Neurobiology of aging 2010, 31, 542-548.

69. Cerf, E.; Sarroukh, R.; Tamamizu-Kato, S.; Breydo, L.; Derclaye, S.; Dufrêne, Y. F.; Narayanaswami, V.; Goormaghtigh, E.; Ruysschaert, J.-M.; Raussens, V., Antiparallel B-sheet: a signature structure of the oligomeric amyloid B-peptide. Biochem. J. 2009, 421, (3), 415-423. 
70. Sarroukh, R.; Cerf, E.; Derclaye, S.; Dufrêne, Y.; Goormaghtigh, E.; Ruysschaert, J.-M.; Raussens, V., Transformation of amyloid $\beta(1-40)$ oligomers into fibrils is characterized by a major change in secondary structure. Cell. Mol. Life Sci. 2011, 68, (8), 1429-1438.

71. Feng, Y.; Wang, X.-P.; Yang, S.-G.; Wang, Y.-J.; Zhang, X.; Du, X.-T.; Sun, X.-X.; Zhao, M.; Huang, L.; Liu, R.-t., Resveratrol inhibits beta-amyloid oligomeric cytotoxicity but does not prevent oligomer formation. Neurotoxicology 2009, 30, (6), 986-995.

72. Woods, L. a.; Platt, G. W.; Hellewell, A. L.; Hewitt, E. W.; Homans, S. W.; Ashcroft, A. E.; Radford, S. E., Ligand binding to distinct states diverts aggregation of an amyloid-forming protein. Nat. Chem. Biol. 2011, 7, (10), 730-9.

73. Necula, M.; Kayed, R.; Milton, S.; Glabe, C. G., Small molecule inhibitors of aggregation indicate that amyloid beta oligomerization and fibrillization pathways are independent and distinct. The Journal of biological chemistry 2007, 282, (14), 10311-24.

74. Wang, X.-p.; Zhang, J.-h.; Wang, Y.-j.; Feng, Y.; Zhang, X.; Sun, X.-X.; Li, J.-1.; Du, X.-t.; Lambert, M. P.; Yang, S.-g.; Zhao, M.; Klein, W. L.; Liu, R.-t., Conformation-dependent single-chain variable fragment antibodies specifically recognize beta-amyloid oligomers. FEBS Lett. 2009, 583, (3), 579-84.

75. Kayed, R.; Canto, I.; Breydo, L.; Rasool, S.; Lukacsovich, T.; Wu, J.; Albay, R.; Pensalfini, A.; Yeung, S.; Head, E.; Marsh, J. L.; Glabe, C., Conformation dependent monoclonal antibodies distinguish different replicating strains or conformers of prefibrillar A $\beta$ oligomers. Mol. Neurodegener. 2010, 5, (1), 57-57.

76. Bolognesi, B.; Kumita, J. R.; Barros, T. P.; Esbjorner, E. K.; Luheshi, L. M.; Crowther, D. C.; Wilson, M. R.; Dobson, C. M.; Favrin, G.; Yerbury, J. J., ANS binding reveals common features of cytotoxic amyloid species. ACS Chem. Biol. 2010, 5, (8), 735-40. 
77. Ladiwala, A. R. A.; Perchiacca, J. M.; Fishman, Z. S.; Bhattacharya, M.; Hickey, A. M.; Domigan, B. G.; Dordick, J. S.; Tessier, P. M., Polyphenolic disaccharides endow proteins with unusual resistance to aggregation. Biotechnology and Bioengineering 2012, 109, (7), 1869-1874.

78. Sood, A.; Abid, M.; Sauer, C.; Hailemichael, S.; Foster, M.; Török, B.; Török, M., Disassembly of preformed amyloid beta fibrils by small organofluorine molecules. Bioorg. Med. Chem. Lett. 2011, $21,(7), 2044-7$.

79. Lee, D.; Lee, E.-K.; Lee, J.-H.; Chang, C.-S.; Paik, S. R., Self-oligomerization and protein aggregation of $\alpha$-synuclein in the presence of Coomassie Brilliant Blue. Eur. J. Biochem. 2001, 268, (2), 295-301.

80. Ha, C.; Park, C. B., Template-directed self-assembly and growth of insulin amyloid fibrils. Biotechnol. Bioeng. 2005, 90, (7), 848-855.

81. Ku, S. H.; Park, C. B., Highly Accelerated Self-Assembly and Fibrillation of Prion Peptides on Solid Surfaces. Langmuir 2008, 24, (24), 13822-13827.

82. Friedman, R., Aggregation of amyloids in a cellular context: modelling and experiment. The Biochemical journal 2011, 438, (3), 415-26.

83. Dasilva, K. a.; Shaw, J. E.; McLaurin, J., Amyloid-beta fibrillogenesis: structural insight and therapeutic intervention. Exp. Neurol. 2010, 223, (2), 311-21.

84. Gras, S. L.; Waddington, L. J.; Goldie, K. N., Protein Folding, Misfolding, and Disease. Notes 2011, 752, (6), 197-214.

85. Toyama, B. H.; Weissman, J. S., Amyloid structure: conformational diversity and consequences. Annu. Rev. Biochem. 2011, 80, 557-85. 
86. Langkilde, A. E.; Vestergaard, B., Methods for structural characterization of prefibrillar intermediates and amyloid fibrils. FEBS Lett. 2009, 583, (16), 2600-9.

87. Chimon, S.; Shaibat, M. a.; Jones, C. R.; Calero, D. C.; Aizezi, B.; Ishii, Y., Evidence of fibrillike beta-sheet structures in a neurotoxic amyloid intermediate of Alzheimer's beta-amyloid. Nat. Struct. Mol. Biol. 2007, 14, (12), 1157-1164.

88. Stine, W. B.; Dahlgren, K. N.; Krafft, G. a.; LaDu, M. J., In vitro characterization of conditions for amyloid-beta peptide oligomerization and fibrillogenesis. J. Biol. Chem. 2003, 278, (13), 11612-22.

89. Santos, S.; Barcons, V.; Christenson, H. K.; Font, J.; Thomson, N. H., The Intrinsic Resolution Limit in the Atomic Force Microscope: Implications for Heights of Nano-Scale Features. PLoS ONE 2011, 6, (8), e23821.

90. Perczel, A.; Park, K.; Fasman, G. D., Deconvolution of the circular dichroism spectra of proteins: The circular dichroism spectra of the antiparallel $\beta$-sheet in proteins. Proteins: Structure, Function, and Bioinformatics 1992, 13, (1), 57-69.

91. Whitmore, L.; Wallace, B. A., Protein secondary structure analyses from circular dichroism spectroscopy: Methods and reference databases. Biopolymers 2008, 89, (5), 392-400.

92. Greenfield, N. J., Applications of circular dichroism in protein and peptide analysis. Trends in analytical chemistry 1999, 18, (4), 236-244.

93. Pelton, J. T.; McLean, L. R., Spectroscopic methods for analysis of protein secondary structure. Anal. Biochem. 2000, 277, (2), 167-76.

94. Surewicz, W. K.; Mantsch, J. H. H.; Chapman, D., Determination of Protein Secondary Structure by Fourier Transform Infrared Spectroscopy : A Critical Assessment. Biochemistry 1993, 32, (2). 
95. Corrêa, D. H. A.; Ramos, C. H. I., The use of circular dichroism spectroscopy to study protein folding, form and function. J. Biochem. 2009, 3, (5), 164-173.

96. Soto, C.; Castan, E. M., The conformation of Alzheimer's Beta peptide determines the rate of amyloid formation and its resistance to proteolysis. J. Biochem. 1996, 314, 701-707.

97. Vieira, E. P.; Hermel, H.; Möhwald, H., Change and stabilization of the amyloid-beta(1-40) secondary structure by fluorocompounds. Biochim. Biophys. Acta 2003, 1645, (1), 6-14.

98. Tomaselli, S.; Esposito, V.; Vangone, P.; van Nuland, N. a. J.; Bonvin, A. M. J. J.; Guerrini, R.; Tancredi, T.; Temussi, P. a.; Picone, D., The alpha-to-beta conformational transition of Alzheimer's Abeta-(1-42) peptide in aqueous media is reversible: a step by step conformational analysis suggests the location of beta conformation seeding. Chembiochem : a European journal of chemical biology 2006, 7 , (2), 257-67.

99. Greenfield, N. J., Using circular dichroism spectra to estimate protein secondary structure. Nat. Protoc. 2006, 1, (6), 2876-90.

100. Wong, H. E.; Qi, W.; Choi, H.-M.; Fernandez, E. J.; Kwon, I., A Safe, Blood-Brain Barrier Permeable Triphenylmethane Dye Inhibits Amyloid- $\beta$ Neurotoxicity by Generating Nontoxic Aggregates. ACS Chem. Neurosci. 2011, 2, (11), 645-657.

101. Necula, M.; Breydo, L.; Milton, S.; Kayed, R.; van der Veer, W. E.; Tone, P.; Glabe, C. G., Methylene blue inhibits amyloid Abeta oligomerization by promoting fibrillization. Biochemistry 2007, 46, (30), 8850-60.

102. Callaway, N. L.; Riha, P. D.; Wrubel, K. M.; McCollum, D.; Gonzalez-Lima, F., Methylene blue restores spatial memory retention impaired by an inhibitor of cytochrome oxidase in rats. Neurosci. Lett. 2002, 332, (2), 83-86. 
103. Korth, C.; May, B. C.; Cohen, F. E.; Prusiner, S. B., Acridine and phenothiazine derivatives as pharmacotherapeutics for prion disease. Proc. Natl. Acad. Sci. U. S. A. 2001, 98, (17), 9836-41.

104. Borzelleca, J. F.; Hallagan, J. B., Multigeneration study of FD \& C Red No. 3 (erythrosine) in Sprague-Dawley rats. Food Chem. Toxicol. 1990, 28, (12), 813-9.

105. Levitan, H.; Ziylan, Z.; Smith, Q. R.; Takasato, Y.; Rapoport, S. I., Brain uptake of a food dye, erythrosin B, prevented by plasma protein binding. Brain Res. 1984, 322, (1), 131-4.

106. Shin, H.-J.; Lee, E.-K.; Lee, J.-H.; Lee, D.; Chang, C.-S.; Kim, Y.-S.; Paik, S. R., Eosin interaction of $\alpha$-synuclein leading to protein self-oligomerization. Biochim. Biophys. Acta, Protein Struct. Mol. Enzymol. 2000, 1481, (1), 139-146.

107. Gardner, D. F.; Utiger, R. D.; Schwartz, S. L.; Witorsch, P.; Meyers, B.; Braverman, L. E.; Witorsch, R. J., Effects of oral erythrosine $\left(2^{\prime}, 4^{\prime}, 5^{\prime}, 7^{\prime}\right.$-tetraiodofluorescein) on thyroid function in normal men. Toxicol. Appl. Pharmacol. 1987, 91, (3), 299-304.

108. Hirohashi, T.; Terasaki, T.; Shigetoshi, M.; Sugiyama, Y., In Vivo and In Vitro Evidence for Nonrestricted Transport of $2^{\prime}, 7^{\prime}$-Bis(2-Carboxyethyl)-5(6)-Carboxyfluorescein Tetraacetoxymethyl Ester at the Blood-Brain Barrier. J. Pharmacol. Exp. Ther. 1997, 280, (2), 813-819.

109. Remy, M.; Thaler, S.; Schumann, R. G.; May, C. a.; Fiedorowicz, M.; Schuettauf, F.; Grüterich, M.; Priglinger, S. G.; Nentwich, M. M.; Kampik, a.; Haritoglou, C., An in vivo evaluation of Brilliant Blue $\mathrm{G}$ in animals and humans. Br. J. Ophthalmol. 2008, 92, (8), 1142-7.

110. Peng, W.; Cotrina, M. L.; Han, X.; Yu, H.; Bekar, L.; Blum, L.; Takano, T.; Tian, G.-F.; Goldman, S. A.; Nedergaard, M., Systemic administration of an antagonist of the ATP-sensitive receptor P2X7 improves recovery after spinal cord injury. Proc. Natl. Acad. Sci. U. S. A. 2009, 106, (30), 12489-12493. 
111. Borzelleca Joseph, F.; Hallagan John, B., Safety and Regulatory Status of Food, Drug, and Cosmetic Color Additives. In Food Safety Assessment, American Chemical Society: 1992; Vol. 484, pp $377-390$.

112. Borzelleca, J. F.; Depukat, K.; Hallagan, J. B., Lifetime toxicity/carcinogenicity studies of FD \& C blue No. 1 (Brilliant blue FCF) in rats and mice. Food Chem. Toxicol. 1990, 28, (4), 221-234.

113. Ryu, J. K.; McLarnon, J. G., Block of purinergic P2X7 receptor is neuroprotective in an animal model of Alzheimer's disease. NeuroReport 2008, 19, (17), 1715-1719.

114. Matute, C.; Torre, I.; Pérez-Cerdá, F.; Pérez-Samartín, A.; Alberdi, E.; Etxebarria, E.; Arranz, A. M.; Ravid, R.; Rodríguez-Antigüedad, A.; Sánchez-Gómez, M.; Domercq, M., P2X7 Receptor Blockade Prevents ATP Excitotoxicity in Oligodendrocytes and Ameliorates Experimental Autoimmune Encephalomyelitis. J. Neurosci. 2007, 27, (35), 9525-9533.

115. Simmons, R.; Thevarajah, S.; Brennan, M.; Christos, P.; Osborne, M., Methylene Blue Dye as an Alternative to Isosulfan Blue Dye for Sentinel Lymph Node Localization. Ann. Surg. Onc. 2003, 10, (3), 242-247.

116. Thevarajah, S.; Huston, T. L.; Simmons, R. M., A comparison of the adverse reactions associated with isosulfan blue versus methylene blue dye in sentinel lymph node biopsy for breast cancer. Am. J. Surg. 2005, 189, (2), 236-239.

117. Zoungrana, A.; Coulibaly, B.; Sié, A.; Walter-Sack, I.; Mockenhaupt, F. P.; Kouyaté, B.; Schirmer, R. H.; Klose, C.; Mansmann, U.; Meissner, P.; Müller, O., Safety and Efficacy of Methylene Blue Combined with Artesunate or Amodiaquine for Uncomplicated Falciparum Malaria: A Randomized Controlled Trial from Burkina Faso. PLoS ONE 2008, 3, (2), e1630.

118. Medina, D. X.; Caccamo, A.; Oddo, S., Methylene Blue Reduces A $\beta$ Levels and Rescues Early Cognitive Deficit by Increasing Proteasome Activity. Brain Pathol. 2011, 21, (2), 140-149. 
119. http://gwyddion.net/ (Accessed August 27th, 2012),

120. Provencher, S. W.; Gloeckner, J., Estimation of globular protein secondary structure from circular dichroism. Biochemistry 1981, 20, (1), 33-37.

121. Vanstokkum, I., Estimation of protein secondary structure and error analysis from circular dichroism spectra. Anal. Biochem. 1990, 191, (1), 110-118.

122. Sreerama, N.; Woody, R. W., Estimation of Protein Secondary Structure from Circular Dichroism Spectra: Comparison of CONTIN, SELCON, and CDSSTR Methods with an Expanded Reference Set. Anal. Biochem. 2000, 287, (2), 252-260.

123. Sreerama, N.; Venyaminov, S. Y.; Woody, R. W., Estimation of Protein Secondary Structure from Circular Dichroism Spectra: Inclusion of Denatured Proteins with Native Proteins in the Analysis. Anal. Biochem. 2000, 287, (2), 243-251.

124. Lees, J. G.; Miles, A. J.; Wien, F.; Wallace, B. A., A reference database for circular dichroism spectroscopy covering fold and secondary structure space. Bioinformatics 2006, 22, (16), 1955-1962.

125. Del Mercato, L. L.; Maruccio, G.; Pompa, P. P.; Bochicchio, B.; Tamburro, A. M.; Cingolani, R.; Rinaldi, R., Amyloid-like Fibrils in Elastin-Related Polypeptides: Structural Characterization and Elastic Properties. Biomacromolecules 2008, 9, (3), 796-803.

126. Pires, R. H.; Saraiva, M. J.; Damas, A. M.; Kellermayer, M. S. Z., Structure and assemblydisassembly properties of wild-type transthyretin amyloid protofibrils observed with atomic force microscopy. J. Mol. Recognit. 2011, 24, (3), 467-476.

127. Harada, T.; Kuroda, R., CD measurements of $\beta$-amyloid (1-40) and (1-42) in the condensed phase. Biopolymers 2011, 95, (2), 127-34. 
128. Soto, C.; Castaño, E. M.; Frangione, B.; Inestrosa, N. C., The -Helical to -Strand Transition in the Amino-terminal Fragment of the Amyloid -Peptide Modulates Amyloid Formation. J. Biol. Chem. 1995, 270, (7), 3063-3067.

129. Chen, Y.-R.; Glabe, C. G., Distinct Early Folding and Aggregation Properties of Alzheimer Amyloid- $\beta$ Peptides A $\beta 40$ and A $\beta 42$. J. Biol. Chem. 2006, 281, (34), 24414-24422.

130. Hu, Y.; Su, B.; Kim, C.-S.; Hernandez, M.; Rostagno, A.; Ghiso, J.; Kim, J. R., A strategy for designing a peptide probe for detection of $\beta$-amyloid oligomers. ChemBioChem 2010, 11, (17), 240918.

131. Williams, A. D.; Sega, M.; Chen, M.; Kheterpal, I.; Geva, M.; Berthelier, V.; Kaleta, D. T.; Cook, K. D.; Wetzel, R., Structural properties of A $\beta$ protofibrils stabilized by a small molecule. Proc. Natl. Acad. Sci. U. S. A. 2005, 102, (20), 7115-7120.

132. Iijima, K.; Liu, H. P.; Chiang, A. S.; Hearn, S. A.; Konsolaki, M.; Zhong, Y., Dissecting the pathological effects of human A beta 40 and A beta 42 in Drosophila: A potential model for Alzheimer's disease. Proc. Natl. Acad. Sci. U. S. A. 2004, 101, (17), 6623-6628.

133. Kimura, N.; Yanagisawa, K.; Terao, K.; Ono, F.; Sakakibara, I.; Ishii, Y.; Kyuwa, S.; Yoshikawa, Y., Age-related changes of intracellular A beta in cynomolgus monkey brains. Neuropathol. Appl. Neurobiol. 2005, 31, (2), 170-180.

134. Klyubin, I.; Walsh, D. M.; Lemere, C. A.; Cullen, W. K.; Shankar, G. M.; Betts, V.; Spooner, E. T.; Jiang, L. Y.; Anwyl, R.; Selkoe, D. J.; Rowan, M. J., Amyloid beta protein immunotherapy neutralizes A beta oligomers that disrupt synaptic plasticity in vivo. Nat. Med. (N. Y., NY, U. S.) 2005, 11, (5), 556-561. 
135. Thakker, D. R.; Weatherspoon, M. R.; Harrison, J.; Keene, T. E.; Lane, D. S.; Kaemmerer, W. F.; Stewart, G. R.; Shafer, L. L., Intracerebroventricular amyloid-beta antibodies reduce cerebral amyloid angiopathy and associated micro-hemorrhages in aged Tg2576 mice. Proc. Natl. Acad. Sci. U. S. A. 2009, 106, (11), 4501-4506.

136. Tycko, R., Progress towards a molecular-level structural understanding of amyloid fibrils. Current Opinion in Structural Biology 2004, 14, (1), 96-103. 


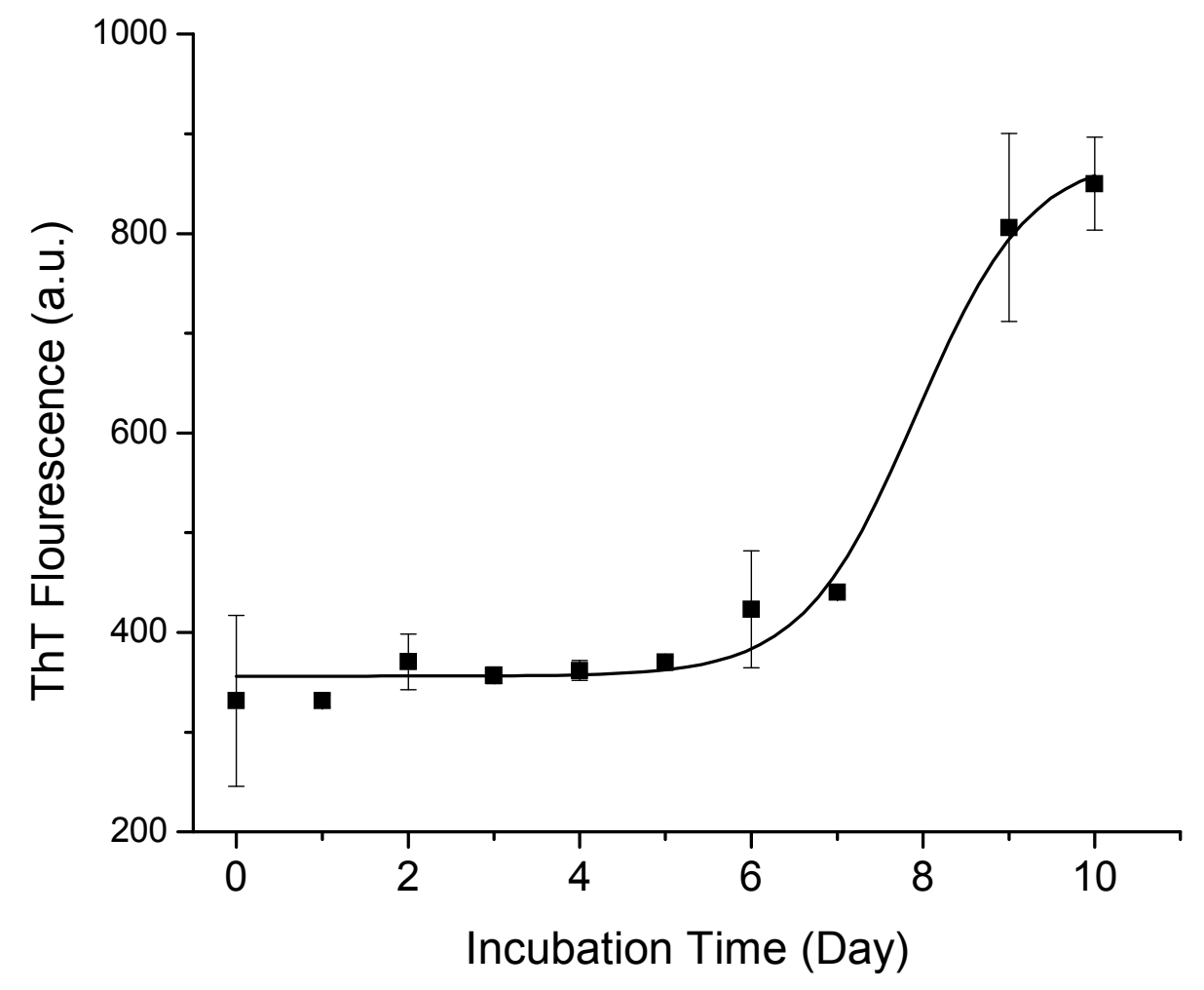

Figure S1: ThT fluorescence monitoring during $A \beta$ fibril formation $(\mathrm{N} \geq 2)$. The data were fit into a sigmoidal curve $(\mathrm{R} 2=0.99)$. 
$A \beta$ only

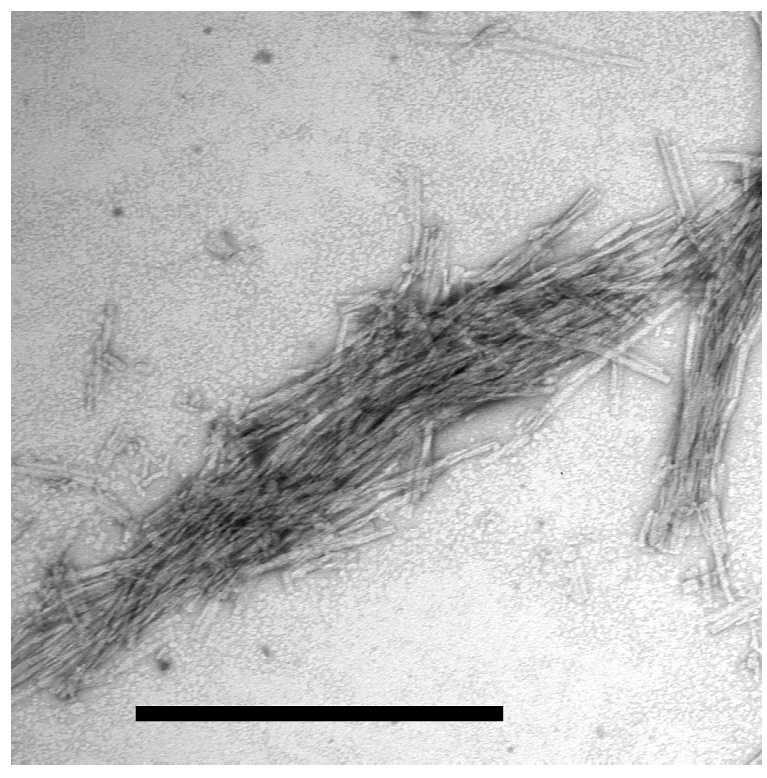

ER

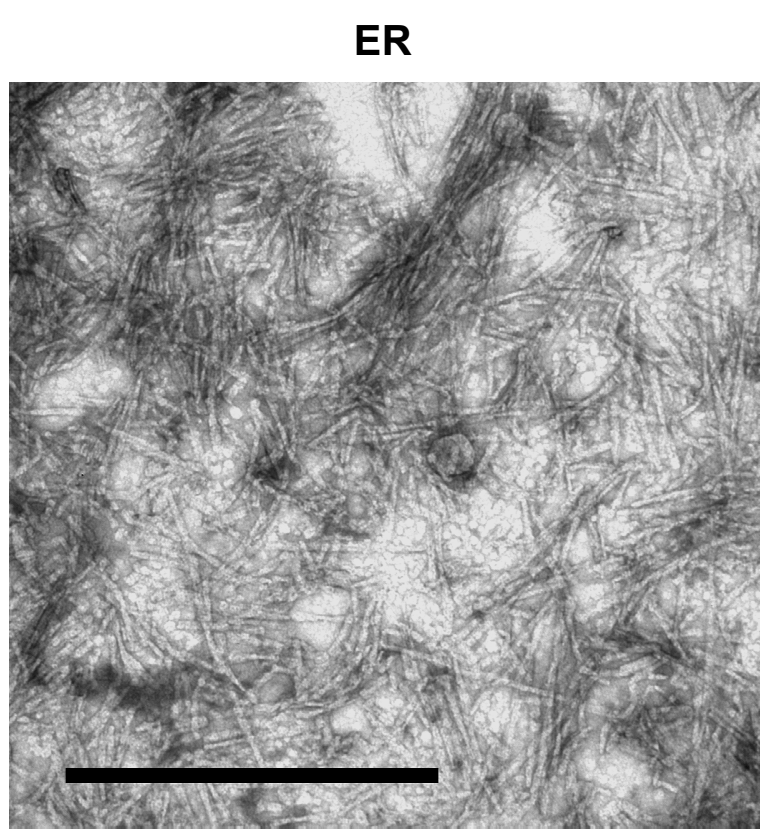

BBG

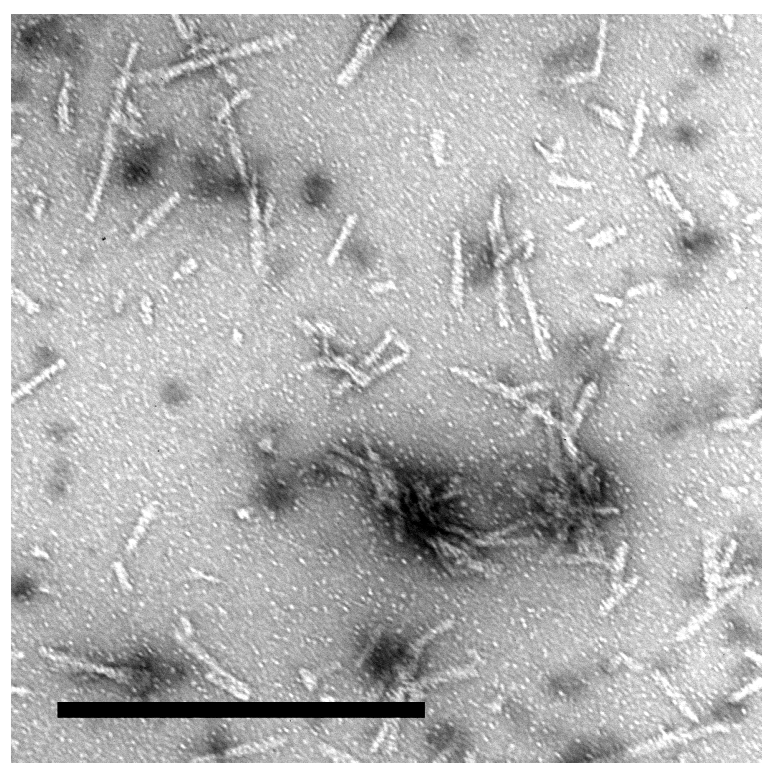

Figure S2: Wider-frame ( $1 \mu \mathrm{m} \times 1 \mu \mathrm{m}$ panel view) TEM images of A $\beta$ fibrils incubated in the absence (A $\beta$ only panel) or presence of 10X BBG (BBG panel) and 10X ER (ER panel). Scale bars are all 500 nm. 
Table S1. Measured ${ }^{\mathrm{a}}$ AFM length (A) and width (B) distribution ${ }^{\mathrm{b}}$ of $\mathrm{A} \beta$ fibrils incubated in the presence or absence of 10X BBG and 10X ER for one day at 37 degrees Celsius.

A.

\begin{tabular}{|c|c|c|c|c|c|c|c|c|c|c|c|}
\hline & & \multicolumn{7}{|c|}{ Length of A $\beta$ Aggregates $(\mu \mathrm{m})$} & \\
\hline & Sample Size & 0.05 & 0.1 & 0.15 & 0.2 & 0.25 & 0.3 & 0.35 & 0.4 & $>0.4$ & $\begin{array}{c}\text { Average } \\
(\mathrm{nm})\end{array}$ \\
\hline $\begin{array}{c}\text { Fibrils } \\
\text { Only }\end{array}$ & 23 & ND & ND & $17 \%$ & $13 \%$ & $13 \%$ & $9 \%$ & $4 \%$ & $9 \%$ & $35 \%$ & $329 \pm 161$ \\
\hline $\begin{array}{c}10 X \\
\text { BBG }\end{array}$ & 141 & $5 \%$ & $58 \%$ & $26 \%$ & $10 \%$ & $1 \%$ & ND & $1 \%$ & ND & ND & $96 \pm 40$ \\
\hline $10 X$ ER & 103 & ND & $15 \%$ & $33 \%$ & $35 \%$ & $6 \%$ & $8 \%$ & $3 \%$ & $1 \%$ & ND & $162 \pm 60$ \\
\hline
\end{tabular}

B.

\begin{tabular}{|c|c|c|c|c|c|c|c|c|c|c|c|c|c|c|c|}
\hline & & \multicolumn{13}{|c|}{ Width of $A \beta$ Aggregates $(\mathrm{nm})$} & \multirow[b]{2}{*}{$\begin{array}{c}\text { Average } \\
(\mathrm{nm})\end{array}$} \\
\hline & $\begin{array}{c}\text { Sample } \\
\text { Size }\end{array}$ & 20 & 25 & 30 & 35 & 40 & 45 & 50 & 55 & 60 & 65 & 70 & 75 & $>75$ & \\
\hline $\begin{array}{c}\text { Fibrils } \\
\text { Only }\end{array}$ & 98 & $\begin{array}{l}\mathrm{N} \\
\mathrm{D}\end{array}$ & $\begin{array}{l}\mathrm{N} \\
\mathrm{D}\end{array}$ & ND & $2 \%$ & $1 \%$ & $1 \%$ & $7 \%$ & $15 \%$ & $15 \%$ & $5 \%$ & $7 \%$ & $6 \%$ & $40 \%$ & $73 \pm 23$ \\
\hline $\begin{array}{c}10 \mathrm{X} \\
\mathrm{BBG}\end{array}$ & 116 & $\begin{array}{l}\mathrm{N} \\
\mathrm{D}\end{array}$ & $\begin{array}{l}\mathrm{N} \\
\mathrm{D}\end{array}$ & $1 \%$ & $1 \%$ & $3 \%$ & $9 \%$ & $16 \%$ & $26 \%$ & $10 \%$ & $9 \%$ & $9 \%$ & $6 \%$ & $10 \%$ & $58 \pm 14$ \\
\hline $\begin{array}{c}10 X \\
\text { ER }\end{array}$ & 116 & $1 \%$ & $3 \%$ & $20 \%$ & $29 \%$ & $26 \%$ & $15 \%$ & $5 \%$ & $1 \%$ & ND & $\begin{array}{l}\mathrm{N} \\
\mathrm{D}\end{array}$ & $\begin{array}{l}\mathrm{N} \\
\mathrm{D}\end{array}$ & $\begin{array}{l}\mathrm{N} \\
\mathrm{D}\end{array}$ & ND & $35 \pm 6$ \\
\hline
\end{tabular}

${ }^{\mathrm{a}}$ Measured using Gwyddion SPM analysis software.

${ }^{b}$ The aggregate length or width bin labels represent the maximum length or width of aggregates in each respective bin. Shown on the table are the proportions of each sample population measured possessing the respective maximum bin length or width.

ND: Not Detected 
Table S2. Secondary structure content $\mathrm{t}^{\mathrm{a}}$ of $\mathrm{A} \beta$ fibrils incubated $^{\mathrm{b}}$ in the absence or presence of MB analyzed using SP175 Reference Set.

\begin{tabular}{|c|c|c|c|c|}
\hline Small molecule added $^{\mathrm{c}}$ & $\alpha$-helix & $\beta$-sheet & $\beta$-turn & Unordered \\
\hline- & $12.2 \%$ & $36.4 \%$ & $12.1 \%$ & $39.3 \%$ \\
\hline MB & $8.4 \%$ & $37.3 \%$ & $12.9 \%$ & $41.3 \%$ \\
\hline
\end{tabular}

${ }^{a}$ Determined by DichroWeb using CONTIN method and SP175 reference proteins

${ }^{\mathrm{b}}$ Incubated at $37^{\circ} \mathrm{C}$ without shaking for one day.

${ }^{\mathrm{c}} \mathrm{A} \beta: \mathrm{MB}=1: 10$ molar ratio 